Cellulose

\title{
Multi-functional coating of cellulose nanocrystals for flexible packaging applications --Manuscript Draft--
}

\begin{tabular}{|c|c|}
\hline \multicolumn{2}{|l|}{ Manuscript Number: } \\
\hline Full Title: & Multi-functional coating of cellulose nanocrystals for flexible packaging applications \\
\hline Article Type: & Original Research \\
\hline Keywords: & $\begin{array}{l}\text { Cellulose nanocrystals (CNs); food packaging; oxygen barrier; anti-fog properties; } \\
\text { bio-coating }\end{array}$ \\
\hline Corresponding Author: & $\begin{array}{l}\text { Fei LI, Ph.D. } \\
\text { Università degli Studi di Milano } \\
\text { Milan, ITALY }\end{array}$ \\
\hline \multicolumn{2}{|l|}{$\begin{array}{l}\text { Corresponding Author Secondary } \\
\text { Information: }\end{array}$} \\
\hline Corresponding Author's Institution: & Università degli Studi di Milano \\
\hline \multicolumn{2}{|l|}{$\begin{array}{l}\text { Corresponding Author's Secondary } \\
\text { Institution: }\end{array}$} \\
\hline First Author: & Fei LI, Ph.D. \\
\hline \multicolumn{2}{|l|}{ First Author Secondary Information: } \\
\hline \multirow[t]{5}{*}{ Order of Authors: } & Fei LI, Ph.D. \\
\hline & Paolo Biagioni, Ph.D. \\
\hline & Monica Bollani, Ph.D. \\
\hline & Andrea Maccagnan \\
\hline & Luciano Piergiovanni, Professor \\
\hline \multicolumn{2}{|c|}{ Order of Authors Secondary Information: } \\
\hline Abstract: & $\begin{array}{l}\text { In this paper, we systematically address the performance of cellulose nanocrystals } \\
\text { (CNs)- coated flexible food packaging films. Firstly, the morphology of CNs from cotton } \\
\text { linters and homogeneity of its coating on different substrates were characterized by } \\
\text { transmission electronic microscopy and atomic force microscopy. Then, the } 1.5 \mu \mathrm{m} \\
\text { thick CNs coating on polyethylene terephthalate (PET), oriented polypropylene (OPP), } \\
\text { orientated polyamide (OPA), and cellophane films were characterized for their } \\
\text { mechanical, optical, anti-fog, and barrier properties. CNs coating reduces the } \\
\text { coefficient of friction while maintaining high transparency }(\sim 90 \%) \text { and low haze }(3-4 \%) \\
\text { values, and shows remarkable oxygen barrier (Oxygen coefficient permeability of CNs } \\
\text { coating, KPO2, } 0.003 \mathrm{~cm} 3 \mathrm{~m}-224 \mathrm{~h}-1 \mathrm{kPa}-1) \text {. In addition, the Gelbo flex test combined } \\
\text { with PO2 measurements and optical microscopy are firstly reported for evaluating the } \\
\text { durability of coatings, revealing that the CNs-coated PET and OPA provide the best } \\
\text { performance among the investigated coated films. CNs are therefore considered to be } \\
\text { a promising multi-functional coating for flexible food packaging. }\end{array}$ \\
\hline \multirow[t]{3}{*}{ Suggested Reviewers: } & $\begin{array}{l}\text { Tsuguyuki Saito, Ph. D. } \\
\text { Assistant Professor, The University of Tokyo } \\
\text { asaitot@mail.ecc.u-tokyo.ac.jp } \\
\text { He is an expert of TEMPO cellulose nanofibres and has plenty of publications on nano- } \\
\text { cellulose applications including coating. }\end{array}$ \\
\hline & $\begin{array}{l}\text { Nathalie GONTARD, Ph. D. } \\
\text { Professor, Université Montpellier II } \\
\text { guillard@univ-montp2.fr } \\
\text { She is a food packaging expert who is researching on new packaging materials with } \\
\text { nanotechnology. }\end{array}$ \\
\hline & $\begin{array}{l}\text { José M. Kenny, Ph. D. } \\
\text { Professor, University of Pergia }\end{array}$ \\
\hline
\end{tabular}


jkenny@unipg.it

He leads his group working on bionanocomposites including using the cellulose nanocrystals.

Markus Linder, Ph. D.

Professor, VTT

markus.linder@vtt.fi

He has been working on nano-cellulose for many years and has plenty of publications on it. 


\section{Cover letter}

Milan, $21^{\text {st }}$ Mar., 2013

\section{Dear Editor,}

I am pleased to enclose here an electronic copy of the original research manuscript entitled "Multi-functional coating of cellulose nanocrystals for flexible packaging applications" for publication on Cellulose.

The present manuscript describes the morphology and multiple functions of cellulose nanocrystals (CNs) which is a safe and sustainable nano-material produced from cotton linters by acid-hydrolysis method. Such thin CNs coating significantly improves the mechanical, anti-fog, and barrier properties, while maintaining excellent optical properties.

Firstly, CNs dispersion is coated on four different conventional flexible packaging materials, including polyethylene terephthalate (PET), oriented polypropylene (OPP), oriented polyamide (OPA), and cellophane (CELL). The morphology and homogeneity of CNs coating on different substrates were characterized by atomic force microscopy (AFM). Secondly, the uniform CNs coating (a) reduces the coefficient of friction (COF) resulting in less opportunity of bio-film formation; (b) maintains high transparency and low haze values so that the customers can clearly see the products inside; (c) exhibits excellent anti-fog property determined by calculated surface energy and its components from static and dynamic contact angles values; (d) performs very good oxygen barrier even after Gelbo flex test and improves the water vapour barrier. In addition, we find that the long entangled cellulose fibres are not the only crucial point for obtaining high gas barrier and that different $\mathrm{COF}$ and oxygen permeability are attributed to the interaction between CNs and various substrates. We conclude that a multi-functional $\mathrm{CNs}$ coating is promising for flexible packaging applications. Therefore, we are expecting that publishing on Cellulose might strongly contribute and accelerate technology transfer in this specific field.

The Authors understand the objectives of Cellulose and I have formatted the manuscript to fit the style and the needs of the Journal. We also understand the procedure that will be followed in the review process. I declare that the manuscript has been prepared for and sent only to Cellulose for publication consideration and it has not been submitted to any other Journal at this time. I attest to the fact that all Authors listed on the title page have directly participated in the planning, execution, and in the discussion of the results of this study. They also have read the manuscript, attested to the validity and legitimacy of the data and their interpretation, and agree to its submission to Cellulose. Also, we prefer "Free online colour".

I hope that you consider this manuscript. If there is anything else that you would like to know, please don't hesitate to get in touch with me. 
Looking forward to hearing from you soon.

Best regards,

\section{Fei LI}

DeFENS, Department of Food, Environmental and Nutritional Sciences - Packaging Division Università degli Studi di Milano

Via Celoria, 220133 MILAN, ITALY

tel. +390250316654

fax +390250316672

fei.li@unimi.it

www.defens.unimi.it

http://users.unimi.it/packlab 

nanocrystals for flexible packaging applications

4 Fei Li, ${ }^{\text {a* }}$ Paolo Biagioni, ${ }^{\mathrm{b}}$ Monica Bollani, ${ }^{\mathrm{c}}$ Andrea.Maccagnan, ${ }^{\mathrm{d}}$ Luciano 5 Piergiovanni $^{\mathrm{a}}$

$6{ }^{a}$ DeFENS - Department of Food, Environmental and Nutritional Sciences -

7 Packaging Division, Università degli Studi di Milano, Via Celoria, 2 - 20133 8 Milano - Italy

$9{ }^{b}$ Dipartimento di Fisica and CNISM, Politecnico di Milano, Piazza L. da Vinci, 1032 - 20133 Milano - Italy

$11{ }^{c}$ IFN-CNR, L-NESS, via Anzani 42, 22100 Como - Italy

$12{ }^{d}$ Packaging Division, GOGLIO S.p.A., Via dell'Industria 721020 Daverio (VA) 13 Italy

14

$15 *$ Corresponding author:

16 E-mail: fei.li@unimi.it

17 Telephone: +3902.50316654

18 Fax: +3902.50316672 


\section{Abstract}

20 In this paper, we systematically address the performance of cellulose nanocrystals (CNs)- coated

21 flexible food packaging films. Firstly, the morphology of $\mathrm{CNs}$ from cotton linters and 22 homogeneity of its coating on different substrates were characterized by transmission electronic

23 microscopy and atomic force microscopy. Then, the $1.5 \mu \mathrm{m}$ thick CNs coating on polyethylene

24 terephthalate (PET), oriented polypropylene (OPP), orientated polyamide (OPA), and cellophane

25 films were characterized for their mechanical, optical, anti-fog, and barrier properties. CNs coating

26 reduces the coefficient of friction while maintaining high transparency ( 90\%) and low haze (3-

$274 \%$ ) values, and shows remarkable oxygen barrier (Oxygen coefficient permeability of CNs

28 coating, $\mathrm{KPO} 2,0.003 \mathrm{~cm}^{3} \mathrm{~m}^{-2} 24 \mathrm{~h}^{-1} \mathrm{kPa}^{-1}$ ). In addition, the Gelbo flex test combined with PO2

29 measurements and optical microscopy are firstly reported for evaluating the durability of coatings,

30 revealing that the CNs-coated PET and OPA provide the best performance among the investigated

31 coated films. CNs are therefore considered to be a promising multi-functional coating for flexible

32 food packaging.

33

34 Keywords: Cellulose nanocrystals (CNs); food packaging; oxygen barrier; anti35 fog properties; bio-coating 


\section{Introduction}

37 Nowadays, the vast majority of food packaging materials is constituted of petrol-

38 based plastics, increasing the dependency of the global economy on fossil

39 resources. Therefore, considering also environmental problems, the interest in bio-

40 based materials, such as poly lactic acid (PLA) (Vert et al., 1995, Drumright et al.,

41 2000, Auras et al., 2004, Lim et al., 2008), starch (Tharanathan, 2003, Avella et

42 al., 2005) or other bio-polymers (Cha and Chinnan, 2004, No et al., 2007, Rhim

43 and Ng, 2007, Hansen and Plackett, 2008, Muzzarelli et al., 2012) has recently

44 been hugely rising. However, such materials are not yet widely applicable because

45 of their inferior properties (Ray et al., 2002, Krikorian and Pochan, 2003, Ray et

46 al., 2003) and high cost, compared with conventional ones, and still many

47 challenges exist before substituting bio-based materials for conventional plastics.

49 The use of plastic materials for flexible food packaging also poses a challenge in

50 finding appropriate strategies to improve their barrier properties. In current

51 research, inorganic coating, such as aluminum (Chatham, 1996, Lange and Wyser,

52 2003) and $\mathrm{SiO}_{2}$ (Erlat et al., 1999, Haas et al., 1999, Creatore et al., 2002) or

53 nano-clays fillers (Sánchez-Valdes et al., 2006, Priolo et al., 2010, Ghasemi et al.,

54 2012, Svagan et al., 2012), are used as oxygen or water vapor barriers with

55 inevitable disadvantages that include a tendency to crack (Priolo et al., 2010) and

56 potential health risks (Lordan et al., 2011). Therefore, a sound strategy consists in

57 partially replacing conventional petrol-based plastics with bio-based materials, for

58 instance, utilizing bio-coatings with the two-fold aim of improving the original

59 plastic properties and reducing the plastic use. Bio-coatings can, therefore, be

60 considered as one of the suitable solutions for food packaging applications. 
61 Nevertheless, the number of directly related bio-coating publications is still

62 limited. Gelatin (Farris et al., 2009) or pullulan (Farris et al., 2012) have been

63 recently reported as oxygen barriers on PET or OPP plastic films. Isogai and his

64 group (Kato et al., 2005) compared the oxygen barrier properties of $12 \mu \mathrm{m}$-thick

65 PET films coated by TEMPO-oxidized microcrystalline cellulose, chitosan and

66 starch, whilst TEMPO-oxidized nano-fiber coatings have been demonstrated as an

67 oxygen barrier on PLA and PET film (Fukuzumi et al., 2009, Fujisawa et al.,

68 2011, Rodionova et al., 2012). Besides cast coating, some research groups

69 successfully improved barrier properties of food packaging materials through

70 layer-by-layer (LbL) assembly (Jang et al., 2008, de Mesquita et al., 2010, Priolo

71 et al., 2010, Zhang and Sun, 2010, Yang et al., 2011, Svagan et al., 2012, Li et al.,

72 2013). However, at present TEMPO-oxidized and LbL coating processes are still

73 difficult to apply at the industrial scale due to their cost and process complexity.

75 In this work, we investigate the physical, mechanical, and optical properties of a

76 bio-coating made of cellulose nanocrystals (CNs), which can be obtained from the

77 most abundant natural polymer on Earth. Besides the promising results that are

78 discussed throughout the paper, such material brings advantages also in terms of

79 low weight, low cost, and biodegradability. Over the last few years, CNs have

80 been extracted from different original sources by chemical, physical, enzymatic

81 processes, or a combination of them (Siró and Plackett, 2010). However, physical

82 and enzymatic processes imply high cost and high energy consumption,

83 respectively, hence we chose a chemical-hydrolysis method for CNs production

84 from cotton linters and we deposited them on different conventional flexible food

85 packaging materials to produce a multi-functional coating. In particular, we used a

86 dispersion of $\mathrm{CNs}$ as the coating material deposited on PET, OPP, OPA and 
87 cellophane films. The morphology, coefficient of friction, anti-fog, optical,

88 oxygen barrier and water vapor barrier properties of coated films were measured

89 and systematically interpreted. 


\section{Materials and methods}

\section{$91 \quad$ Materials.}

92 Cotton linters were provided by S.S.C.C.P. (Milan, Italy) as the raw material to 93 produce $\mathrm{CNs}$.

94 Four different plastic substrates were coated and used for experiments: (1) 95 poly(ethylene terephthalate) (PET, 12 $\pm 0.5 \mu \mathrm{m}$ thickness), (2) oriented 96 polypropylene (OPP, $20 \pm 0.5 \mu \mathrm{m}$ thickness), (3) oriented polyamide (OPA, $12 \pm 0.5$ $97 \mu \mathrm{m}$ thickness), and cellophane (CELL, $12 \pm 0.5 \mu \mathrm{m}$ thickness). All plastic films 98 have been provided by Radici Film, San Giorgio di Nogaro, Italy.

100 Methods.

101 CNs extraction.

$1021 \mathrm{wt} \%$ Cellulose nanocrystals (CNs) dispersion was produced from cotton linter

103 by a procedure described elsewhere (Li et al., 2013). Briefly, milled cotton linters 104 were hydrolyzed by $64 \mathrm{wt} \%$ sulfuric acid with vigorous stirring at $45{ }^{\circ} \mathrm{C}$ for 45 105 minutes. The reaction mixture was diluted with deionized water and then rinsed 106 and centrifuged at $5000 \mathrm{rpm}$ repeatedly until the supernatant became turbid. 107 Further purification was then done by dialysis against deionized water (Molecular

108 Weight Cut Off 12000 and higher). Sequentially, the suspension was sonicated

109 (UP400S $400 \mathrm{~W}$, Hielscher Co., Germany) to create cellulose crystals of colloidal 110 dimensions. Finally, the suspension was filtered under vacuum with Muktell 111 (grade GF/C, $1.2 \mu \mathrm{m}$ pore diameter) and Whatman glass microfiber filter (grade $112 \mathrm{GF} / \mathrm{F}, 0.7 \mu \mathrm{m}$ pore diameter) to remove contamination and big aggregations. The 113 CNs content of the resulting aqueous suspension was determined by drying 
114 several samples $\left(1 \mathrm{ml}\right.$ each) at $105{ }^{\circ} \mathrm{C}$ for $15 \mathrm{~min}$ intervals (to avoid

115 decomposition or burning) until weight constancy, giving a cellulose

116 concentration of $\sim 1 \mathrm{wt} \%$ and a yield of $\sim 50 \%$. To prepare a given concentration of

117 CNs solution, the resulting $\mathrm{CNs}$ dispersion was adjusted to $\mathrm{pH} \sim 7$ by $1 \mathrm{M}$

$118 \mathrm{NaOH}(\mathrm{aq})$, freeze-dried and stored in tightly sealed container under dry

119 conditions for later analysis and experiments.

\section{Particle size distribution}

$1221 \%$ CNs dispersion was scanned by a laser diffraction particle size analyzer

123 (Mastersizer 2000, Malvern Instruments), combining a blue source with $470 \mathrm{~nm}$

124 wavelength and a red source with $632.8 \mathrm{~nm}$ wavelength.

126 Preparation of Coating Dispersion.

127 An 8 wt\% CNs water dispersion was obtained by dissolving the CNs into distilled 128 water assisted with ultrasonic treatments until the dispersion became visually

129 homogenous. During the process, the sonication should be carried out every ten

130 minute in water bath to avoid overheating. After recovering to room temperature,

131 the CNs dispersion was coated on different plastic films.

133 Coated Film Preparation.

134 According to ASTM D823-07, practice C, the corona-treated sides (external sides) 135 of four different rectangular $\left(25 \times 20 \mathrm{~cm}^{2}\right)$ plastic films were coated by an 136 automatic film applicator (ref 1137, Sheen Instruments, Kingston, U.K.) at a 137 constant speed of $2.5 \mathrm{~mm} \mathrm{~s}^{-1}$. Water was evaporated using a constant mild air flow 
$138\left(25 \pm 0.3{ }^{\circ} \mathrm{C}\right.$ for $\left.5 \mathrm{~min}\right)$ at a perpendicular distance of $40 \mathrm{~cm}$ from the automatic

139 applicator. The coated films were stored under controlled conditions $\left(20 \pm 2{ }^{\circ} \mathrm{C}\right.$,

$14045 \pm 2.0 \% \mathrm{RH}$ ) for $24 \mathrm{~h}$, and then stored in sealed anhydrous desiccators for $24 \mathrm{~h}$

141 before analysis. All substrates are distinguished by external (Ex) and internal (In)

142 sides. The external side is the pre-treated part, while the internal side is without

143 corona treatments.

\section{Thickness measurements}

146 For the coating thickness measurement, a $10 \times 10 \mathrm{~cm}^{2}$ sample (plastic substrate 147 with coating) was cut and weighed $\left(m_{1}, \mathrm{~g}\right)$. The coating was then removed by 148 running hot water $\left(\sim 70{ }^{\circ} \mathrm{C}\right)$ and the resulting bare film was weighed $\left(m_{2}, \mathrm{~g}\right)$. The 149 coating thickness $(l, \mu \mathrm{m})$ was obtained according to the following equation:

$$
l=\frac{m_{1}-m_{2}}{\rho} \times 100
$$

151 where $\rho \sim 1.58 \mathrm{~g} \mathrm{~cm}^{-3}$ is the density of CNs (Mazeau and Heux, 2003). Three 152 measurements were performed for each coating type.

154 Microscopy

155 Transmission Electron Microscopy (TEM)

156 Drops of aqueous dispersions of CNs (0.05 wt\%) were deposited on carbon157 coated electron microscope grids, negatively stained with uranyl acetate and 158 allowed to dry. The samples were analyzed with a Hitachi Jeol-10084 TEM 159 operated at an accelerating voltage of $80 \mathrm{kV}$. 


\section{Atomic force microscopy (AFM)}

162 AFM topography images have been acquired in tapping mode with a Veeco

163 Innova instrument. Super-sharp silicon probes (typical radius of curvature $2 \mathrm{~nm}$ )

164 have been used for high-resolution imaging of nanocrystals, while standard silicon

165 probes have been employed for large-area scans in order to evaluate the sample

166 roughness.

167 The root mean square roughness $S$ is calculated as the standard deviation of the 168 topography

$169(M \times N$ pixels $)$ :

$$
S=\sqrt{\frac{1}{M N} \sum_{i=i}^{M} \sum_{j=1}^{N}\left|z\left(x_{i}, y_{j}\right)-\bar{z}\right|^{2}},
$$

171 where $z$ is the mean value of the topography $z(x, y)$.

\section{Optical microscopy}

174 Gelbo Flex treated CNs-coated samples were observed using an optical 175 microscope (Micro Nikon Eclipse ME600 Laboratory Imaging; Nikon 176 Instruments, Sesto Fiorentino, Italy) at $5 \times$ and $10 \times$ magnification. Pieces of film

$177\left(30 \times 30 \mathrm{~mm}^{2}\right)$ were mounted on a rectangular glass sample holder and observed 178 without any pretreatment. Images were captured by NIS-Element software (Nikon 179 Instruments, Sesto Fiorentino, Italy).

182 The static $\left(\mu_{\mathrm{S}}\right)$ and dynamic $\left(\mu_{\mathrm{d}}\right)$ friction coefficients were measured by a 183 dynamometer (model Z005, Zwick Roell, Ulm, Germany), in accordance with the 
184 standard method ASTM D 1894-87. The software TestXpert V10.11 (Zwick

185 Roell, Ulm, Germany) Master was used for data analysis.

186

187 Optical properties

188 Transparency measurements

189 The transmittance of the sample was measured at a wavelength of $550 \mathrm{~nm}$,

190 according to the ASTM D 1746-70, by means of a spectro-photometer (model

191 L650, Perkin-Elmer, Milano, Italy).

192

193 Haze

194 Haze was measured in accordance with ASTM D 1003-61 by means of a 195 spectrophotometer (Perkin Elmer L650). The haze values of uncoated and coated 196 films were obtained as:

$$
\text { haze }=100 \times \frac{I_{S}}{I_{T}},
$$

198 where $I_{\mathrm{s}}$ and $I_{\mathrm{T}}$ are the scattered and total transmitted light, respectively.

\section{Contact angle measurements}

201 Contact angles were measured to estimate the surface energies of the tested 202 substrates by OCA 15 Plus angle goniometer (Data Physics Instruments GmbH, 203 Filderstadt, Germany). The software (SCA20 and SCA21) provided by the 204 instrument manufacturer calculate the surface energy based on contact angles 205 measurements. Measurements of static and advancing contact angle were 206 performed at room temperature with two polar liquids and one apolar liquid: 
207 Milli-Q water, formamide (FOM, $\geq 99.5 \%$, Carlo Erba, Milano, Italy), and

208 diiodomethane (DIM, 99\%, Sigma Aldrich), respectively. Each measurement was

209 repeated on at least five different positions for each sample. The surface energies

210 were calculated from the contact angle data at equilibrium by the Van Oss method

211 (van Oss, 2006), which divides the total surface free energy into two components,

212 the dispersive and the polar components, where the polar interactions originate

213 from the Lewis acid-base interactions:

214

$$
\gamma_{i}^{\text {total }}=\gamma_{i}^{D}+\gamma_{i}^{P}
$$

216 where

$$
\gamma_{i}^{P}=2 \sqrt{\gamma_{i}^{+} \gamma_{i}^{-}}
$$

218 The subscripts $i$ indicate the solid $(i=s)$ or liquid $(i=l)$ phase, and the superscripts

219 refer to the dispersive (D) and polar (P) components of the total surface energy.

$220 \gamma^{+}$and $\gamma^{-}$are electron-acceptor and donor parts of the Lewis acid-base

221 interactions.

222

223 When combined with Young's equation, the equations developed by Chaudhury,

224 Good, and Van Oss yield the equation (van Oss, 2006)

$$
\gamma_{l}(1+\cos \theta)=2\left(\sqrt{\gamma_{l}^{D} \gamma_{s}^{D}}+\sqrt{\gamma_{s}^{+} \gamma_{l}^{-}}+\sqrt{\gamma_{s}^{-} \gamma_{l}^{+}}\right.
$$

226 where $\theta$ is the contact angle, $\gamma_{l}$ is the liquid surface tension $\left(\mathrm{mJ} \mathrm{m}^{-2}\right)$, and $\gamma_{s}^{+}$,

$227 \gamma_{s}^{-}$and $\gamma_{l}^{+}, \gamma_{l}^{-}$are electron-acceptor and donor contributions to the polar

228 component of the solid and liquid, respectively $\left(\mathrm{mJ} \mathrm{m}^{-2}\right)$. The values of the surface

229 tension and its components for each liquid that were used in calculations were 
230 determined by Van Oss (van Oss, 2003). Water, formamide, and diiodomethane,

231 with known $\gamma_{l}^{D}, \gamma_{l}^{+}$, and $\gamma_{l}^{-}$values (Table 1) and measured contact angle $(\theta)$

232 were used to determine $\gamma_{s}^{D}, \gamma_{s}^{+}$, and $\gamma_{s}^{-}$combined with Equation (6). Finally,

$233 \gamma_{s}^{\text {total }}$ and $\gamma_{s}^{P}$ were calculated from Equation (4) and (5).

234

Table 1

236 Oxygen and water vapor permeability $\left(P_{\mathrm{O} 2}\right.$ and $\left.P_{\mathrm{H} 2 \mathrm{O}}\right)$ measurements.

237 The $\mathrm{P}_{\mathrm{O} 2}$ and $\mathrm{P}_{\mathrm{H} 2 \mathrm{O}}$ of $\mathrm{CNs}$ coated plastic films were measured by permeation 238 instruments (MOCON, OX-TRAN ${ }^{\circledR}$ Model 702 and PERMATRAN-W ${ }^{\circledR}$ Model 239700 ) at $23{ }^{\circ} \mathrm{C}$ and $0 \%$ relative humidity (RH) and at $38{ }^{\circ} \mathrm{C}$ and $100 \% \mathrm{RH}$ 240 difference, complying with ASTM D-3985, F-1927, F-1307 and ASTM F-1249, 241 respectively.

243 The $\mathrm{P}_{\mathrm{O} 2}$ of the CNs coating in the coated film [i.e., $\mathrm{P}_{\mathrm{O} 2}$ (Coating)] was calculated 244 using the following equation:

$$
\frac{1}{P_{O 2}(\text { coating })}=\frac{1}{P_{O 2}(\text { coated film })}-\frac{1}{P_{O 2}(\text { film })},
$$

246 where $\mathrm{P}_{\mathrm{O} 2}$ (coated film) and $\mathrm{P}_{\mathrm{O} 2}($ film) are the oxygen permeabilities for the coated 247 substrate and the bare substrate, respectively.

249 Gelbo Flex testing

250 According to slightly modified ASTM F392, the CNs-coated samples were treated 251 by 20 cycles with Gelbo Flex tester (model S/N 8003 32, VINATORU 252 ENTERPRISES INC, Graham, USA), shown in Fig. 1. Each cycle includes back 
253 and forth steps with $440^{\circ}$ on long stroke. After treatments, the samples were

254 observed by optical microscopy and the oxygen permeability was measured 255 according to the method above.

256

257 Fig. 1 


\section{Results and discussion}

\section{Morphology}

261 Fig. 2

265 The rod-like CNs produced by sulfuric acid hydrolysis of cotton linters were 266 characterized by TEM as shown in Fig. 2. CNs observations obtained from casted 267 diluted dispersion (approximate $0.05 \mathrm{wt} \%$ ) show individual nanocrystals and 268 some aggregates. The appearance of aggregated elementary crystallites in TEM 269 images is expected due to the high specific area and strong hydrogen bonds 270 established between the CNs. From several TEM images, the mean values of the 271 length $(L)$ and diameter $(d)$ of the isolated CNs were determined to be $120 \pm 30 \mathrm{~nm}$ 272 and $6 \pm 3 \mathrm{~nm}$, respectively, giving an aspect ratio $(L / d) \sim 20$. Similar dimensions

273 have been reported in the literature (Angles and Dufresne, 2000, Elazzouzi274 Hafraoui et al., 2007). In order to better understand the CNs size distribution, the 275 probability histogram for the particle size distribution of $1 \% \mathrm{CNs}$ dispersion is 276 shown in Fig. 3. It indicates that the range of the CNs length is from 90 to $160 \mathrm{~nm}$ 277 (mean value $\sim 115 \mathrm{~nm}$ ), which is highly similar with the results obtained from 278 TEM (Fig. 2) and in other references (Habibi et al., 2010). A certain degree of size 279 distribution is inevitable owing to the acid diffusion-controlled nature of the 280 hydrolysis (de Mesquita et al., 2010). However, the results demonstrate that the 281 acidic hydrolysis process is highly reliable and effective to extract relatively 282 uniform CNs from cotton linters. 
284 Fig. 4

286 Fig. 4 shows high-resolution AFM images of CNs-coated films. The image shows

287 a dense packing and uniform coverage of nanofibers. We therefore conclude that a

288 new CNs layer was homogeneously established on different conventional 289 packaging materials. Dense packing of CNs has been previously described in 290 other reports (Fujisawa et al., 2011). The continuous layer of overlapping CNs 291 fibers (Siró and Plackett, 2010) points towards possible improvements of the 292 oxygen barrier properties of the different substrates, which we will demonstrate 293 and discuss later on. Moreover, we acquired large-area AFM images, as shown in 294 Fig. 5, where CNs cobble-stone pathway-like aggregations appear due to the 295 strong hydrogen bonds. All images are qualitatively very similar with each other. 296 Root-mean-square roughness values calculated from such AFM investigations all 297 lay in a low-value range $(6-13 \mathrm{~nm})$, which is definitely more narrow than the one 298 measured for the external side of bare films (2-21 nm, not shown). A low 299 roughness has been correlated to a less opportunity for bio film formation 300 (Shellenberger and Logan, 2001, Li and Logan, 2004, Ringus and Moraru, 2013), 301 thus bacterial fouling occurrence can be likely reduced by such a coating when 302 applied onto rough substrates. 
Table 2

313 The values for the coefficient of friction (COF) of CNs-coated films against films

314 are presented in Table 2. By means of the statistical analysis, we again can

315 conclude that the casting deposition created a completely new CNs-coating layer

316 on different substrates with one exception. In fact, it can be clearly noted that

317 three of the investigated systems (coated-PET, OPA, and CELL) present similar

318 values in dynamic $\left(\mu_{\mathrm{d}}\right)$ COFs, while only CNs-coated OPP is significantly

319 different from the other coated films and close to the bare one, probably due to

320 weak adhesion between CNs coating and OPP surface which leads to the removal

321 of CNs from substrate during dynamic measurements. The COF results and

322 oxygen permeability discussed later indicate that for thin CNs coating a

323 homogenous independent layer was established by cast coating. It is thus

324 concluded that CNs coating results in an improvement for practical applications,

325 because of the reduction of friction between the films, which might represent a

326 premium feature for high-speed packaging machineries.

328 Optical properties.

Table 3

332 As for optical properties, the transparency and haze values of bare films are 87-

$33392 \%$ and $2.1-3.0 \%$, respectively, while the ones of coated films are $88-91 \%$ and 
334 3.3-4.0\%. Detailed results in Table 3 show that the CNs-coated films still

335 maintain high transparency, as requested to ensure easy evaluation of the product

336 quality inside the package. Although their haze values increase, the maximum

337 values (4\%) are yet within an acceptable range. Overall, the thin CNs coating

$338(\sim 1.5 \mu \mathrm{m}$, as determined by weighting the samples) has no significant influences

339 on the optical properties of coated films.

\section{Anti-fog properties.}

342 Besides the COF improvements and maintaining excellent optical properties, 343 empirical boiling water and breathe (Huff) tests both showed that the CNs-coated

344 films have excellent anti-fog properties, which are presented in Fig. 6.

345 Particularly, we deposited CNs directly on different substrates without any 346 primers or any chemicals to guarantee the safety of food contact. In Fig. 6 we

347 show the results for the coated OPP film since OPP is the most hydrophobic

348 material among the substrates under investigation, but very similar results were

349 obtained for all the substrates. We observed the border [blue dashed line in panels

350 (b) and (c)] between bare and coated films by eye inspection. In order to better

351 observe the anti-fog property, we set a black sponge in the water containers, as

352 shown in Fig. 6(b). As known, fog is formed by small discontinuous water

353 droplets that diffuse the incident light, thereby decrease the transparency and

354 increase the haze (Nuraje et al., 2010, Introzzi et al., 2012). Fig. 6 (c), obtained

355 with optical microscopy, presents two parts, an uncoated one with water droplets,

356 which forms fog, and a coated one with a homogeneous water layer without any

357 droplets, which remained transparent. In the following part, we will further 
358 interpret the excellent anti-fog properties of CNs-coated films from the

359 comparison of surface energies obtained from contact angle goniometry.

Fig. 6

362

366 From Table 4, we could notice that the CNs-coated films show highly similar

367 static contact angles, which indicates that a completely new CNs layer was

368 established through cast coating process. The static contact angles of CNs coated

369 substrates are much lower than the ones of bare substrates, since cellulose chains

370 contain many hydroxyl (-OH) groups leading to its hydrophilicity. Meanwhile, the

371 dynamic contact angles, which might better reveal the real behavior of hydrophilic

372 surfaces, were also determined. Moreover, it was reported that the differences

373 between the advancing and receding contact angles are usually related with 374 surface's roughness and water absorption often observed on natural fibers 375 (Dankovich and Gray, 2011).

377 We will use contact angles combined with surface energies of CNs coating to 378 interpret the principles behind the anti-fog performance. The static and dynamic 379 contact angle values (Table 4a and b) are in good agreement with results recently 380 presented on nano-cellulose coated or casted films (Dankovich and Gray, 2011).

381 Regarding the anti-fog properties, it was reported that one possible measure of the 382 level of interaction of water with a material is the advancing contact angle and it 383 has been suggested that hydrophilic surfaces with contact angles lower than $40^{\circ}$ 
384 should exhibit anti-fog behavior (Briscoe and Galvin, 1991, Howarter and

385 Youngblood, 2008). Indeed, the measured advancing contact angle values $\left(\theta_{\text {Water }}\right)$

386 of CNs-coated films are about $26-27^{\circ}$.

390 To further interpret the anti-fog behavior, we calculated the surface energies 391 values from contact angles, presented in Fig. 7, through Lifshitz-van der 392 Waals/acid-base theory. In the literature, the surface energy of cellulose 393 determined by contact angle measurements is known to be $\sim 55 \mathrm{~mJ} \mathrm{~m}^{-2}$ (Aulin et 394 al., 2009). Also, a value for the surface energy of CNs films on different 395 substrates was reported as high as $65 \mathrm{~mJ} \mathrm{~m}^{-2}$ with $\pm 15 \%$ experimental error 396 (Kontturi et al., 2007). These values are consistent with the values obtained in our 397 results of CNs-coated PET and OPP. Contact angles were measured by using 398 water, FOM, and DIM to provide information regarding the contributions of 399 dispersive (D) and polar (P) components to the total surface energy of the 400 substrates. The calculated values in Fig. 7(a) indicate that the dispersive part of 401 the CNs surface energy is larger than the polar contribution as well as the CNs 402 hydrophilic property, we thus further investigate the electron-acceptor and donor 403 components to the polar part of total surface energy shown in Fig. 7(b). From Fig. 404 7(b), bare PET and OPP have different asymmetric electron-acceptor and donor 405 patterns due to PET and OPP being relatively hydrophilic and hydrophobic, 406 respectively, while the $\mathrm{CN}$-coated PET and OPP have similar asymmetric patterns 407 which disclose that the thin $\mathrm{CNs}$ coating results in an independent and 408 homogeneous layer on PET and OPP substrates. This is a common occurrence 409 since, for a given polar substrate, a strong asymmetry is usually observed between 
410 the contribution of electron-acceptor and electron-donor interactions, making one

411 of the two dominant (van Oss, 2006). Furthermore, the electron-donor component

$412\left(\gamma_{s}^{-}\right)$values of coated PET and OPP shown in Fig. 7(b) are at least 5 and 2000

413 times the bare ones, which is likely the fundamental factor for different anti-fog

414 performances between bare and coated films. Also, cellulose always presents a

415 polar and hydrophilic surface (Moon et al., 2011) and CNs are grafted with a few

416 sulfate ester groups $\left(-\mathrm{O}-\mathrm{SO}_{3}^{-}\right)$due to the sulfuric acid hydrolysis process.

417 These results, therefore, suggest that the anti-fog property induced on the PET and

418 OPP substrates should be attributed to the electron-donor parameter of the polar

419 component. For hydrophilic biopolymers, similar results were also reported

420 (Nuraje et al., 2010, Introzzi et al., 2012).

\section{Barrier properties.}

424 Fig. 8

426 In addition to excellent performances on COF, optical, and anti-fog properties, the

427 CNs barrier function is evaluated as follows. Fig. 8(a) shows that the oxygen 428 barrier properties of coated films improve significantly thanks to the thin $(1.5 \mu \mathrm{m})$

429 CNs coating. The coatings allow for a dramatic reduction (>99\%) of oxygen 430 permeability $\left(\mathrm{P}_{\mathrm{O} 2}\right)$ of all CNs-coated samples. Oxygen permeability coefficient

$431\left(\mathrm{KP}_{\mathrm{O} 2}\right)$ of CNs coating on OPA is down to $0.003 \mathrm{~cm}^{3} \mu \mathrm{m} \mathrm{m}^{-2} 24 \mathrm{~h}^{-1} \mathrm{kPa}^{-1}$, which is 432 much lower than that of commercialized oxygen barrier, ethylene vinyl alcohol 433 (EVOH), under dry condition (Lee et al., 2008). Also, this $\mathrm{KP}_{\mathrm{O} 2}$ value is 434 comparable with the best oxygen barrier from wood TEMPO-oxidized cellulose 
nanofiber (TOCN-COONa) (Fukuzumi et al., 2011) and this is, according to our

436 best knowledge, the first systematic report on $\mathrm{P}_{\mathrm{O} 2}$ of CNs-coated films. Such

437 excellent oxygen barrier properties achieved on CNs-coated OPA can be

438 tentatively attributed to the strong hydrogen bonds among CNs and between CNs

439 and OPA. We also calculated the $\mathrm{KP}_{\mathrm{O} 2}$ of $\mathrm{CNs}$ coatings applied on other

440 substrates, finding always an improved barrier compared to the bare substrate.

441 Therefore, our results indicate that $\mathrm{CNs}$ coating provides very good oxygen

442 barrier (especially under dry conditions) but also that the effectiveness of this

443 property is related to the possible interactions between CNs and different plastic

444 films used as coating substrates. One more interesting point is the achievement of

445 high oxygen barrier using short CNs $(\sim 120 \mathrm{~nm})$. In other words it seems to be

446 demonstrated that long entangled cellulose fibers (Belbekhouche et al., 2011) are

447 not the only crucial point in achieving certain functionalities.

449 The $\mathrm{P}_{\mathrm{O} 2}$ of CNs-coated films after Gelbo Flex test is also presented in Fig. 8(a).

450 As known (Habibi et al., 2008, Isogai et al., 2011, Moon et al., 2011), nano-

451 cellulose is stiff and rigid, which should result in fragility of the coating and,

452 thereby, a possible partial loss of the gas barrier properties during usage. Based on

453 the above considerations, we compared the oxygen barrier before and after Gelbo

454 Flex tests. The results indicate that strong distortions led to some destructions of

455 CNs coating and reduce the oxygen barrier properties of all CNs-coated films.

456 Gelbo Flex treated CNs-coated PET and OPA films, however, still maintain a 457 significant low $\mathrm{P}_{\mathrm{O} 2}$. Compared with others, Gelbo Flex treated coated OPP and 458 cellophane films show relatively higher $\mathrm{P}_{\mathrm{O} 2}$, probably due to their weak adhesion, 459 which was also observed in dynamic COF tests especially for OPP. In order to 460 confirm this point, we did observations by optical microscopy and the figures are 
461 presented in Fig. 9. The morphologies of PET and OPA in Fig. 9 (a), and (c)

462 reveal better adhesions between $\mathrm{CNs}$ and PET and OPA, since only a small

463 portion of the CNs film was peeled off from substrates even though there are 464 many chaps (crackles) especially at strongly twisted parts of CNs coatings.

465 However, in case of Gelbo Flex treated CNs-coated OPP, from Fig. 9 (b) we

466 found peeled-off/blister and cracks of CNs coating, which is likely to result in the

467 lower oxygen barrier properties observed. Peeling-off cracks also unexpectedly

468 occurred to cellophane, shown in Fig. 9 (d). This phenomenon might be explained

469 by the presence of resins coated or laminated on the commercialized cellophanes,

470 in this case, low wettable polyester resin. The images from optical microscopy are

471 therefore consistent with the lower oxygen barrier on Gelbo Flex treated coated

472 OPP and cellophane. In this work, the oxygen permeability values were measured

473 only under the dry condition. Since CNs is a hydrophilic biopolymer, the oxygen

474 barrier will be certainly reduced under high RH as other paper reported

475 (Fukuzumi et al., 2012). This limitation is common to the currently used synthetic

476 barrier polymers (polyamide (PA), polyvinyl alcohol (PVOH), ethylene vinyl

477 alcohol (EVOH)) and led to the development of multilayer structures ( $\mathrm{Li}$ et al.,

478 2013), designed in order to protect moisture sensitive polymers with polyolefin

479 such as low-density polyethylene (LDPE), high-density polyethylene (HDPE),

480 and polypropylene (PP).

482 The four coated films were also evaluated for their water vapor permeability $483\left(\mathrm{P}_{\mathrm{H} 2 \mathrm{O}}\right)$ and Fig. 8(b) reports the results obtained. The $\mathrm{P}_{\mathrm{H} 2 \mathrm{O}}$ of CNs-coated PET, 484 OPP, OPA and CELL films is reduced by 22, 26, 24 and $6.5 \%$ respectively, 485 compared to bare films, while the corresponding thickness increase is $7.5 \%$ for 486 OPP and $12.5 \%$ for the other three films. Such a limited improvement of the 
487 moisture barrier is due to CNs hydrophilicity (Hult et al., 2010, Sanchez-Garcia et 488 al., 2010, Moon et al., 2011) and also to the heavy conditions of the test used $489\left(38{ }^{\circ} \mathrm{C}\right.$ under a difference of $\left.100 \% \mathrm{RH}\right)$. However, the water vapor barrier 490 properties of $\mathrm{CNs}$ coating might be satisfactory in real-use conditions which 491 generally involve lower temperature and RH values. Also, high water vapor 492 barrier can already be achieved by conventional and convenient synthetic 493 polymers such as PP and PE.

494

495 Fig. 9 


\section{Conclusions}

497 To the best of our knowledge, this is the first time that CNs are deposited on 498 different substrates as multi-functional coatings. In the literature, CNs are usually

499 considered as a filler (Noorani et al., 2007, Habibi et al., 2008, Siqueira et al.,

500 2010, Goffin et al., 2011, Dong et al., 2012) or used for small-scale spin or layer-

501 by-layer coating (Kontturi et al., 2007, Cranston and Gray, 2008, Cerclier et al.,

502 2010, Hoeger et al., 2011, Li et al., 2013), and are assumed not to function as a

503 practical coating material (Isogai et al., 2011). In this paper, we systematically

504 investigated the properties of conventional films coated with CNs, demonstrating

505 that CNs coatings mainly lead to a reduction of friction, a premium feature for

506 industrial applications, and that they do not influence significantly the optical

507 properties of coated films. Moreover, CNs coating shows excellent anti-fog

508 property, which is a strongly required performance for flexible food packaging,

509 intended to be used for fresh food. Finally, CNs coatings not only dramatically

510 improve the oxygen barrier properties of conventional flexible food packaging

511 material, but also lead to a certain reduction in the water vapor permeability.

512 While substitution of conventional plastics might still be far ahead because of

513 their low cost, large flexibility and availability, the perspective use of CNs as

514 multi-functional coatings to favor a reduction of the required thickness for plastic

515 films, towards a more environmentally-friendly and sustainable approach to

516 packaging seems promising and feasible. The best substrate to be covered with

517 CNs appeared to be PET and OPA films due to their intrinsic polarity and high

518 surface energies; however, the possible use of activation treatments and other

519 plastic substrates remain to be deeply investigated, as well as the possible 
520 measures to reduce the moisture sensitivities and mechanical rigidity of the thin 521 nano-cellulose coatings. 


\section{Acknowledgments}

523 We wish to thank Prof. Franco Faoro from Department of Plant Production, Università degli Studi 524 di Milano (Milano, Italy), who carried out TEM observations, Dr. Roberto Galbasini and Dr. 525 Giorgio Bottini, from Goglio S. p. A. (VA, Italy), who helped in oxygen and water vapor barrier 526 measurements, and Dr. Christian Furiosi from SAPICI S. p. A (Milan, Italy), who helped in 527 particle size distribution measurement. 


\section{References:}

529 Angles MN and Dufresne A (2000) Plasticized starch/tunicin whiskers nanocomposites. 1.

530 Structural analysis. Macromolecules 33, 8344-53.

531 Aulin C, Ahola S, Josefsson P, Nishino T, Hirose Y, Österberg M et al. (2009) Nanoscale

532 Cellulose Films with Different Crystallinities and Mesostructures-Their Surface Properties and 533 Interaction with Water. Langmuir 25, 7675-85.

534 Auras R, Harte B, and Selke S (2004) An overview of polylactides as packaging materials.

535 Macromolecular Bioscience 4, 835-64.

536 Avella M, De Vlieger JJ, Errico ME, Fischer S, Vacca P, and Volpe MG (2005) Biodegradable

537 starch/clay nanocomposite films for food packaging applications. Food Chemistry 93, 467-74.

538 Belbekhouche S, Bras J, Siqueira G, Chappey C, Lebrun L, Khelifi B et al. (2011) Water sorption

539 behavior and gas barrier properties of cellulose whiskers and microfibrils films. Carbohydrate

540 Polymers 83, 1740-8.

541 Briscoe BJ and Galvin KP (1991) The effect of surface fog on the transmittance of light. Solar

542 Energy 46, 191-7.

543 Cerclier C, Cousin F, Bizot H, Moreau C, and Cathala B (2010) Elaboration of Spin-Coated

544 Cellulose-Xyloglucan Multilayered Thin Films. Langmuir 26, 17248-55.

545 Cha DS and Chinnan MS (2004) Biopolymer-based antimicrobial packaging: A review. Critical

546 Reviews in Food Science and Nutrition 44, 223-37.

547 Chatham H (1996) Oxygen diffusion barrier properties of transparent oxide coatings on polymeric

548 substrates. Surface and Coatings Technology 78, 1-9.

549 Cranston ED and Gray DG (2008) Birefringence in spin-coated films containing cellulose 550 nanocrystals. Colloids and Surfaces a-Physicochemical and Engineering Aspects 325, 44-51.

551 Creatore M, Palumbo F, and d'Agostino R (2002) Deposition of SiOx films from 552 hexamethyldisiloxane/oxygen radiofrequency glow discharges: Process optimization by plasma 553 diagnostics. Plasmas and Polymers 7, 291-310.

554 Dankovich TA and Gray DG (2011) Contact Angle Measurements on Smooth Nanocrystalline 555 Cellulose (I) Thin Films. Journal of Adhesion Science and Technology 25, 699-708.

556 de Mesquita JP, Donnici CL, and Pereira FV (2010) Biobased Nanocomposites from Layer-by-

557 Layer Assembly of Cellulose Nanowhiskers with Chitosan. Biomacromolecules 11, 473-80.

558 Dong H, Strawhecker KE, Snyder JF, Orlicki JA, Reiner RS, and Rudie AW (2012) Cellulose

559 nanocrystals as a reinforcing material for electrospun poly(methyl methacrylate) fibers: Formation,

560 properties and nanomechanical characterization. Carbohydrate Polymers 87, 2488-95.

561 Drumright RE, Gruber PR, and Henton DE (2000) Polylactic acid technology. Advanced Materials

562 12, 1841-6.

563 Elazzouzi-Hafraoui S, Nishiyama Y, Putaux J-L, Heux L, Dubreuil F, and Rochas C (2007) The

564 Shape and Size Distribution of Crystalline Nanoparticles Prepared by Acid Hydrolysis of Native

565 Cellulose. Biomacromolecules 9, 57-65. 

barrier coatings on polymer substrates: Morphology and gas transport considerations. Journal of

568 Physical Chemistry B 103, 6047-55.

569 Farris S, Introzzi L, Fuentes-Alventosa JM, Santo N, Rocca R, and Piergiovanni L (2012) Self-

570 Assembled Pullulan-Silica Oxygen Barrier Hybrid Coatings for Food Packaging Applications.

571 Journal of Agricultural and Food Chemistry 60, 782-90.

572 Farris S, Introzzi L, and Piergiovanni L (2009) Evaluation of a bio-coating as a solution to

573 improve barrier, friction and optical properties of plastic films. Packaging Technology and Science $574 \quad 22,69-83$.

575 Fujisawa S, Okita Y, Fukuzumi H, Saito T, and Isogai A (2011) Preparation and characterization

576 of TEMPO-oxidized cellulose nanofibril films with free carboxyl groups. Carbohydrate Polymers $57784,579-83$

578 Fukuzumi H, Saito T, and Isogai A (2012) Influence of TEMPO-oxidized cellulose nanofibril 579 length on film properties. Carbohydrate Polymers,

580 http://dx.doi.org/10.1016/j.carbpol.2012.04.069.

581 Fukuzumi H, Saito T, Iwamoto S, Kumamoto Y, Ohdaira T, Suzuki R et al. (2011) Pore Size

582 Determination of TEMPO-Oxidized Cellulose Nanofibril Films by Positron Annihilation Lifetime

583 Spectroscopy. Biomacromolecules 12, 4057-62.

584 Fukuzumi H, Saito T, Wata T, Kumamoto Y, and Isogai A (2009) Transparent and High Gas

585 Barrier Films of Cellulose Nanofibers Prepared by TEMPO-Mediated Oxidation.

586 Biomacromolecules 10, 162-5.

587 Ghasemi H, Carreau PJ, Kamal MR, and Tabatabaei SH (2012) Properties of PET/clay

588 nanocomposite films. Polymer Engineering and Science 52, 420-30.

589 Goffin AL, Raquez JM, Duquesne E, Siqueira G, Habibi Y, Dufresne A et al. (2011) From

590 Interfacial Ring-Opening Polymerization to Melt Processing of Cellulose Nanowhisker-Filled 591 Polylactide-Based Nanocomposites. Biomacromolecules 12, 2456-65.

592 Haas KH, Amberg-Schwab S, Rose K, and Schottner G (1999) Functionalized coatings based on

593 inorganic-organic polymers (ORMOCER (R) s) and their combination with vapor deposited 594 inorganic thin films. Surface \& Coatings Technology 111, 72-9.

595 Habibi Y, Goffin AL, Schiltz N, Duquesne E, Dubois P, and Dufresne A (2008)

596 Bionanocomposites based on poly(epsilon-caprolactone)-grafted cellulose nanocrystals by ring597 opening polymerization. Journal of Materials Chemistry 18, 5002-10.

598 Habibi Y, Lucia LA, and Rojas OJ (2010) Cellulose Nanocrystals: Chemistry, Self-Assembly, and 599 Applications. Chemical Reviews 110, 3479-500.

600 Hansen NML and Plackett D (2008) Sustainable films and coatings from hemicelluloses: A 601 review. Biomacromolecules 9, 1493-505.

602 Hoeger I, Rojas OJ, Efimenko K, Velev OD, and Kelley SS (2011) Ultrathin film coatings of 603 aligned cellulose nanocrystals from a convective-shear assembly system and their surface 604 mechanical properties. Soft Matter 7, 1957-67.

605 Howarter JA and Youngblood JP (2008) Self-Cleaning and Next Generation Anti-Fog Surfaces 606 and Coatings. Macromolecular Rapid Communications 29, 455-66. 
Hult EL, Iotti M, and Lenes M (2010) Efficient approach to high barrier packaging using

608 microfibrillar cellulose and shellac. Cellulose 17, 575-86.

609 Introzzi L, Fuentes-Alventosa JM, Cozzolino CA, Trabattoni S, Tavazzi S, Bianchi CL et al.

610 (2012) "Wetting Enhancer" Pullulan Coating for Antifog Packaging Applications. ACS Applied

611 Materials \& Interfaces 4, 3692-700.

612 Isogai A, Saito T, and Fukuzumi H (2011) TEMPO-oxidized cellulose nanofibers. Nanoscale 3, 613 71-85.

614 Jang W-S, Rawson I, and Grunlan JC (2008) Layer-by-layer assembly of thin film oxygen barrier.

615 Thin Solid Films 516, 4819-25.

616 Kato Y, Kaminaga J-i, Matsuo R, and Isogai A (2005) Oxygen Permeability and Biodegradability

617 of Polyuronic Acids Prepared from Polysaccharides by TEMPO-Mediated Oxidation. Journal of

618 Polymers and the Environment 13, 261-6.

619 Kontturi E, Johansson LS, Kontturi KS, Ahonen P, Thune PC, and Laine J (2007) Cellulose

620 nanocrystal submonolayers by spin coating. Langmuir 23, 9674-80.

621 Krikorian V and Pochan DJ (2003) Poly (L-lactic acid)/layered silicate nanocomposite:

622 Fabrication, characterization, and properties. Chemistry of Materials 15, 4317-24.

623 Lange J and Wyser Y (2003) Recent innovations in barrier technologies for plastic packaging-a

624 review. Packaging Technology and Science 16, 149-58.

625 Lee DS, Yam KL, and Piergiovanni L (2008) In Food Packaging Science and Technology. Vol.

626 pp. 58-59, 86-93, CRC Press,

627 Li B and Logan BE (2004) Bacterial adhesion to glass and metal-oxide surfaces. Colloids and

628 Surfaces B: Biointerfaces 36, 81-90.

629 Li F, Biagioni P, Finazzi M, Tavazzi S, and Piergiovanni L (2013) Tunable green oxygen barrier

630 through layer-by-layer self-assembly of chitosan and cellulose nanocrystals. Carbohydrate

631 Polymers 92, 2128-34.

632 Lim LT, Auras R, and Rubino M (2008) Processing technologies for poly(lactic acid). Progress in

633 Polymer Science 33, 820-52.

634 Lordan S, Kennedy JE, and Higginbotham CL (2011) Cytotoxic effects induced by unmodified

635 and organically modified nanoclays in the human hepatic HepG2 cell line. Journal of Applied

636 Toxicology 31, 27-35.

637 Mazeau K and Heux L (2003) Molecular Dynamics Simulations of Bulk Native Crystalline and

638 Amorphous Structures of Cellulose. The Journal of Physical Chemistry B 107, 2394-403.

639 Moon RJ, Martini A, Nairn J, Simonsen J, and Youngblood J (2011) Cellulose nanomaterials

640 review: structure, properties and nanocomposites. Chemical Society Reviews 40, 3941-94.

641 Muzzarelli RAA, Boudrant J, Meyer D, Manno N, DeMarchis M, and Paoletti MG (2012) Current

642 views on fungal chitin/chitosan, human chitinases, food preservation, glucans, pectins and inulin:

643 A tribute to Henri Braconnot, precursor of the carbohydrate polymers science, on the chitin

644 bicentennial. Carbohydrate Polymers 87, 995-1012.

645 No HK, Meyers SP, Prinyawiwatkul W, and Xu Z (2007) Applications of chitosan for

646 improvement of quality and shelf life of foods: A review. Journal of Food Science 72, R87-R100. 
647 Noorani S, Simonsen J, and Atre S (2007) Nano-enabled microtechnology: polysulfone 648 nanocomposites incorporating cellulose nanocrystals. Cellulose 14, 577-84.

649 Nuraje N, Asmatulu R, Cohen RE, and Rubner MF (2010) Durable Antifog Films from Layer-by-

650 Layer Molecularly Blended Hydrophilic Polysaccharides. Langmuir 27, 782-91.

651 Priolo MA, Gamboa D, Holder KM, and Grunlan JC (2010) Super Gas Barrier of Transparent 652 Polymer-Clay Multilayer Ultrathin Films. Nano Letters 10, 4970-4.

653 Ray SS, Yamada K, Okamoto M, and Ueda K (2003) New polylactide-layered silicate

654 nanocomposites. 2. Concurrent improvements of material properties, biodegradability and melt 655 rheology. Polymer 44, 857-66.

656 Ray SS, Yamada K, Okamoto M, and Ueda K (2002) Polylactide-layered silicate nanocomposite:

657 A novel biodegradable material. Nano Letters 2, 1093-6.

658 Rhim J-W and Ng PKW (2007) Natural biopolymer-based nanocomposite films for packaging

659 applications. Critical Reviews in Food Science and Nutrition 47, 411-33.

660 Ringus DL and Moraru CI (2013) Pulsed Ligh inactivation of Listeria innocua on food packaging 661 materials of different surface roughness and reflectivity. Journal of Food Engineering 114, 331-7.

662 Rodionova G, Saito T, Lenes M, Eriksen O, Gregersen O, Fukuzumi H et al. (2012) Mechanical

663 and oxygen barrier properties of films prepared from fibrillated dispersions of TEMPO-oxidized

664 Norway spruce and Eucalyptus pulps. Cellulose 19, 705-11.

665 Sánchez-Valdes S, López-Quintanilla ML, Ramírez-Vargas E, Medellín-Rodríguez FJ, and

666 Gutierrez-Rodriguez JM (2006) Effect of Ionomeric Compatibilizer on Clay Dispersion in

667 Polyethylene/Clay Nanocomposites. Macromolecular Materials and Engineering 291, 128-36.

668 Sanchez-Garcia MD, Hilliou L, and Lagaron JM (2010) Morphology and Water Barrier Properties

669 of Nanobiocomposites of k/i-Hybrid Carrageenan and Cellulose Nanowhiskers. Journal of 670 Agricultural and Food Chemistry 58, 12847-57.

671 Shellenberger K and Logan BE (2001) Effect of Molecular Scale Roughness of Glass Beads on

672 Colloidal and Bacterial Deposition. Environmental Science \& Technology 36, 184-9.

673 Siqueira G, Abdillahi H, Bras J, and Dufresne A (2010) High reinforcing capability cellulose

674 nanocrystals extracted from Syngonanthus nitens (Capim Dourado). Cellulose 17, 289-98.

675 Siró I and Plackett D (2010) Microfibrillated cellulose and new nanocomposite materials: a 676 review. Cellulose 17, 459-94.

677 Svagan AJ, Åkesson A, Cárdenas M, Bulut S, Knudsen JC, Risbo J et al. (2012) Transparent Films

678 Based on PLA and Montmorillonite with Tunable Oxygen Barrier Properties. Biomacromolecules $67913,397-405$.

680 Tharanathan RN (2003) Biodegradable films and composite coatings: past, present and future.

681 Trends in Food Science \& Technology 14, 71-8.

682 van Oss CJ (2006) Interfacial Forces in Aqueous Media. In Dekker M (ed.), pp. 18-28 and 93-107. 683 CRC Press, New York.

684 van Oss CJ (2003) Long-range and short-range mechanisms of hydrophobic attraction and 685 hydrophilic repulsion in specific and aspecific interactions. Journal of Molecular Recognition 16, $686 \quad 177-90$. 
687 van Oss CJ, Wu W, Docoslis A, and Giese RF (2001) The interfacial tensions with water and the

688 Lewis acid-base surface tension parameters of polar organic liquids derived from their aqueous 689 solubilities. Colloids and Surfaces B: Biointerfaces 20, 87-91.

690 Vert M, Schwarch G, and Coudane J (1995) Present and Future of PLA Polymers. Journal of 691 Macromolecular Science-Pure and Applied Chemistry A32, 787-96.

692 Yang Y-H, Haile M, Park YT, Malek FA, and Grunlan JC (2011) Super Gas Barrier of All693 Polymer Multilayer Thin Films. Macromolecules 44, 1450-9.

694 Zhang L and Sun J (2010) Layer-by-Layer Codeposition of Polyelectrolyte Complexes and Free 695 Polyelectrolytes for the Fabrication of Polymeric Coatings. Macromolecules 43, 2413-20.

696 


\section{Figure Caption}

698 Fig. 1 Gelbo Flex tester, a, b, and c indicate different phases of a back and forth 699 cycle.

700 Fig. 2 TEM image of individual CNs

701 Fig. 3 Probability histogram for the particle size distribution measured from 1\%

702 CNs dispersion

703 Fig. 4 High-resolution AFM images of CNs-coated PET (a), OPP (b), OPA (c), 704 and CELL (d).

705 Fig. 5 AFM for roughness of coated substrates, coated PET (a), OPP (b), OPA (c), 706 and cellophane $(\mathrm{d})$.

707 Fig. 6 Boiling water test; panel (a) the foggy bare OPP observed with an optical 708 microscope; panel (b) comparison between bare and CNs-coated OPP during the 709 test; panel (c) the border between CNs-coated and bare parts observed with an 710 optical microscope.

711 Fig. 7 Surface energies and their respective polar and dispersive components of 712 bare and CNs-coated PET and OPP, (a); the electron-acceptor and donor of polar 713 component, (b)

714 Fig. 8 The oxygen permeability $\left(\mathrm{P}_{\mathrm{O} 2}\right)$ of bare, CNs-coated, and CNs-coated after 715 Gelbo Flex tests PET, OPP, OPA, and CELL films at $23{ }^{\circ} \mathrm{C}$ under dry condition 716 (a); the water vapor permeability of bare and CNs-coated PET, OPP, OPA, and 717 CELL films at $38{ }^{\circ} \mathrm{C}$ under $100 \%$ RH difference (b).

718 Fig. 9 The morphology of Gelbo Flex treated CNs-coated PET (a), OPP (b), OPA 719 (c), and CELL (d) films by optical microscopy. 
$720 \quad$ Tables

721 Table 1 Surface tension components and parameters of the liquids used in direct

722 contact angle determination in $\mathrm{mJ} \mathrm{m}^{-2}$, at $20{ }^{\circ} \mathrm{C}$ (van Oss et al., 2001, vanOss, 723 2003)

724

725 Table 2 The coefficient of friction (COF) of Plastic films (Ex) against plastic film $726 \quad(\mathrm{In})$

727

728 Table 3 Transparency at $550 \mathrm{~nm}$ and haze of bare and CNs-coated films

729

730 Table 4a Static contact angles of bare and CNs-coated films

731 Table 4b Advancing and receding contact angles of bare and CNs-coated films 732 


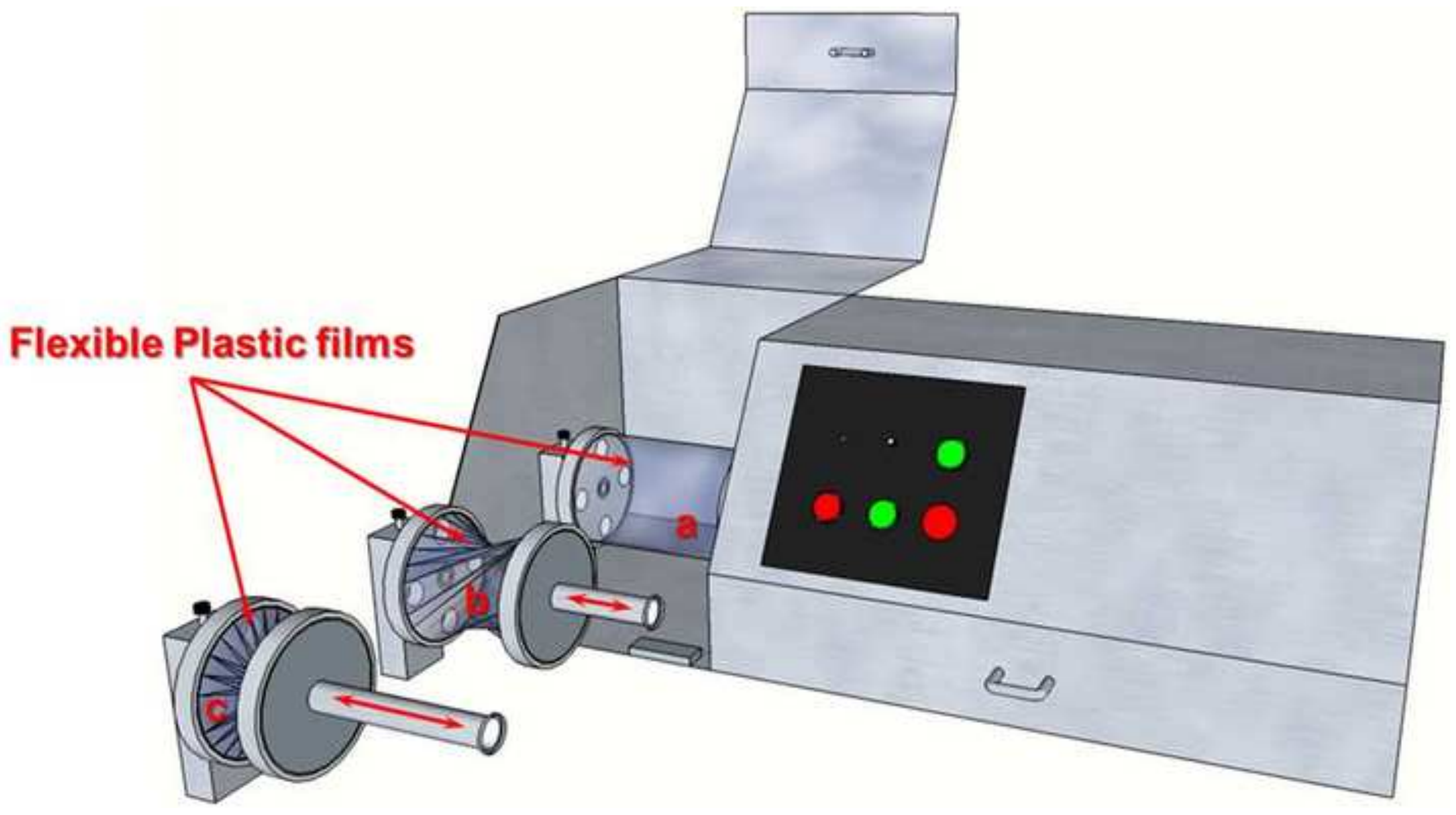


Figure 2
Click here to download high resolution image

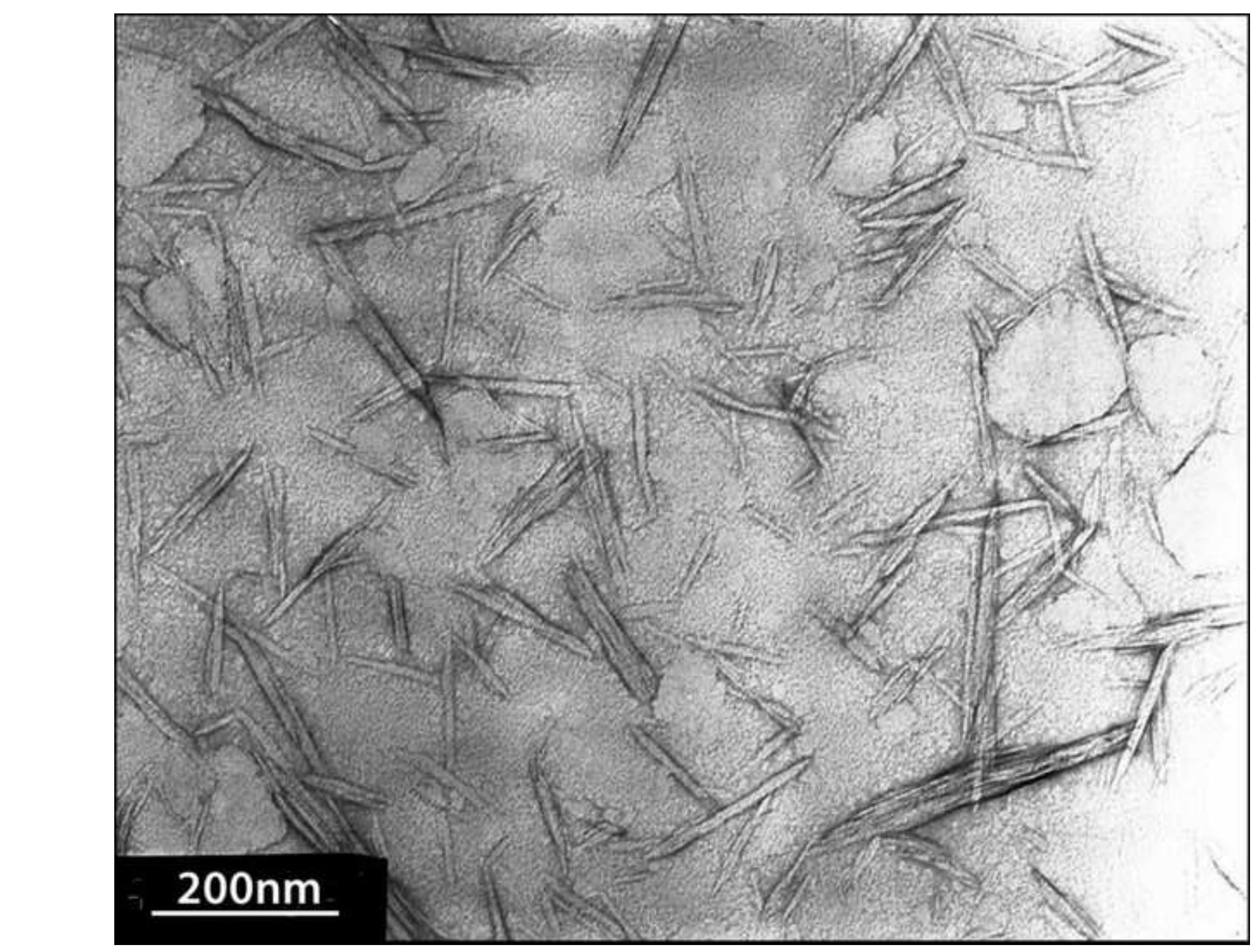




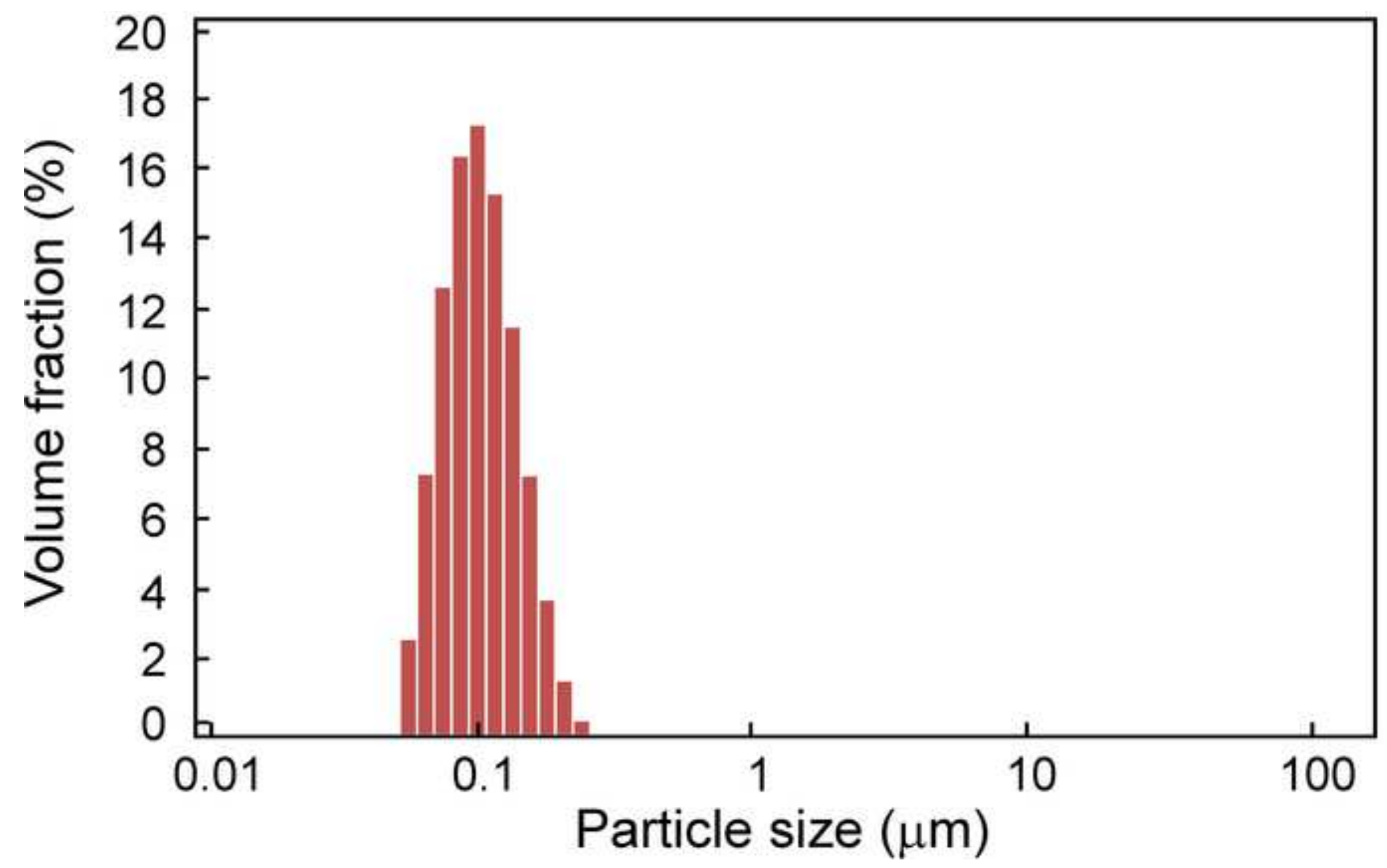


0

90 $\mathrm{nm}$

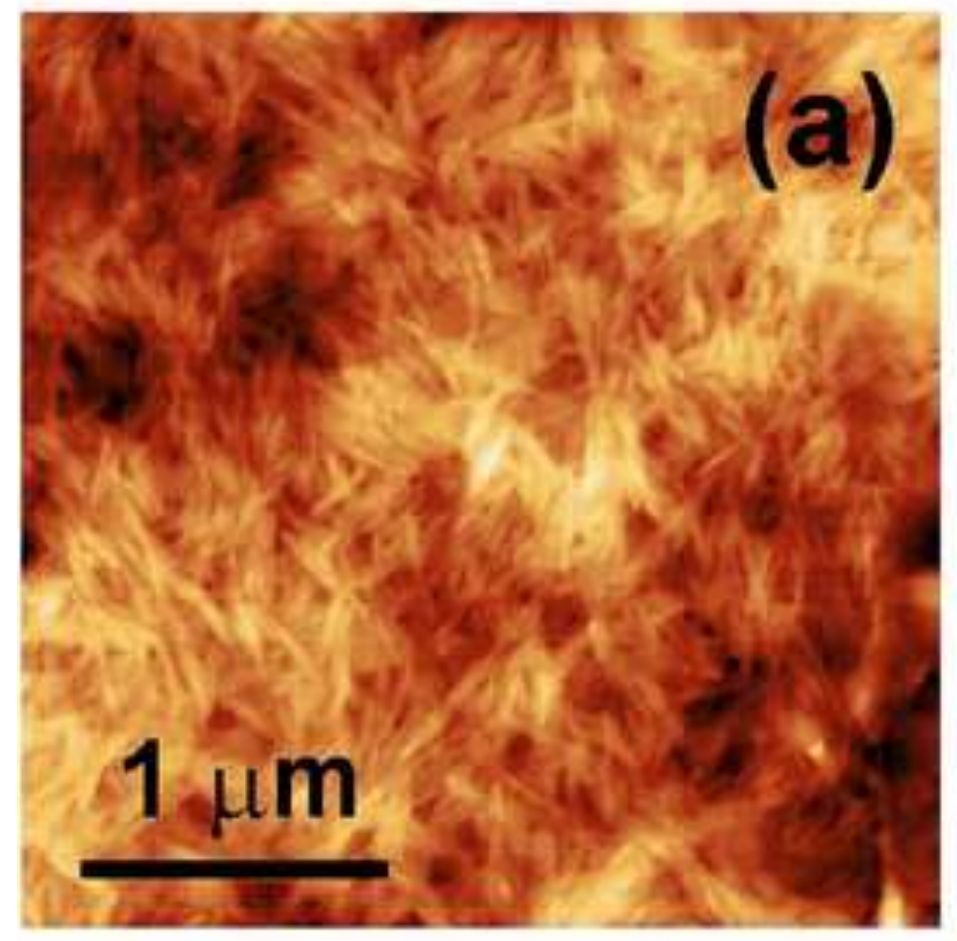

0

80
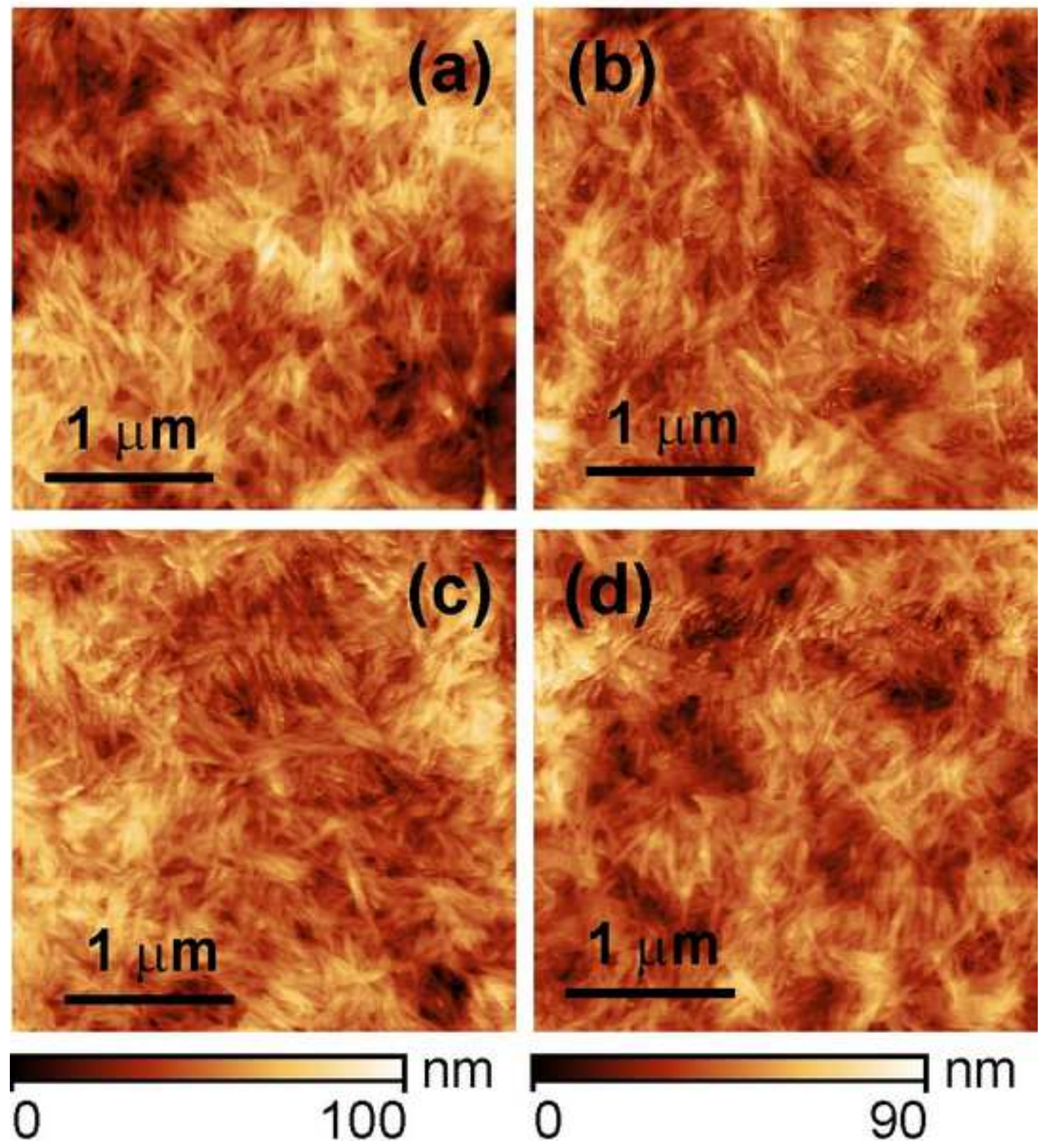

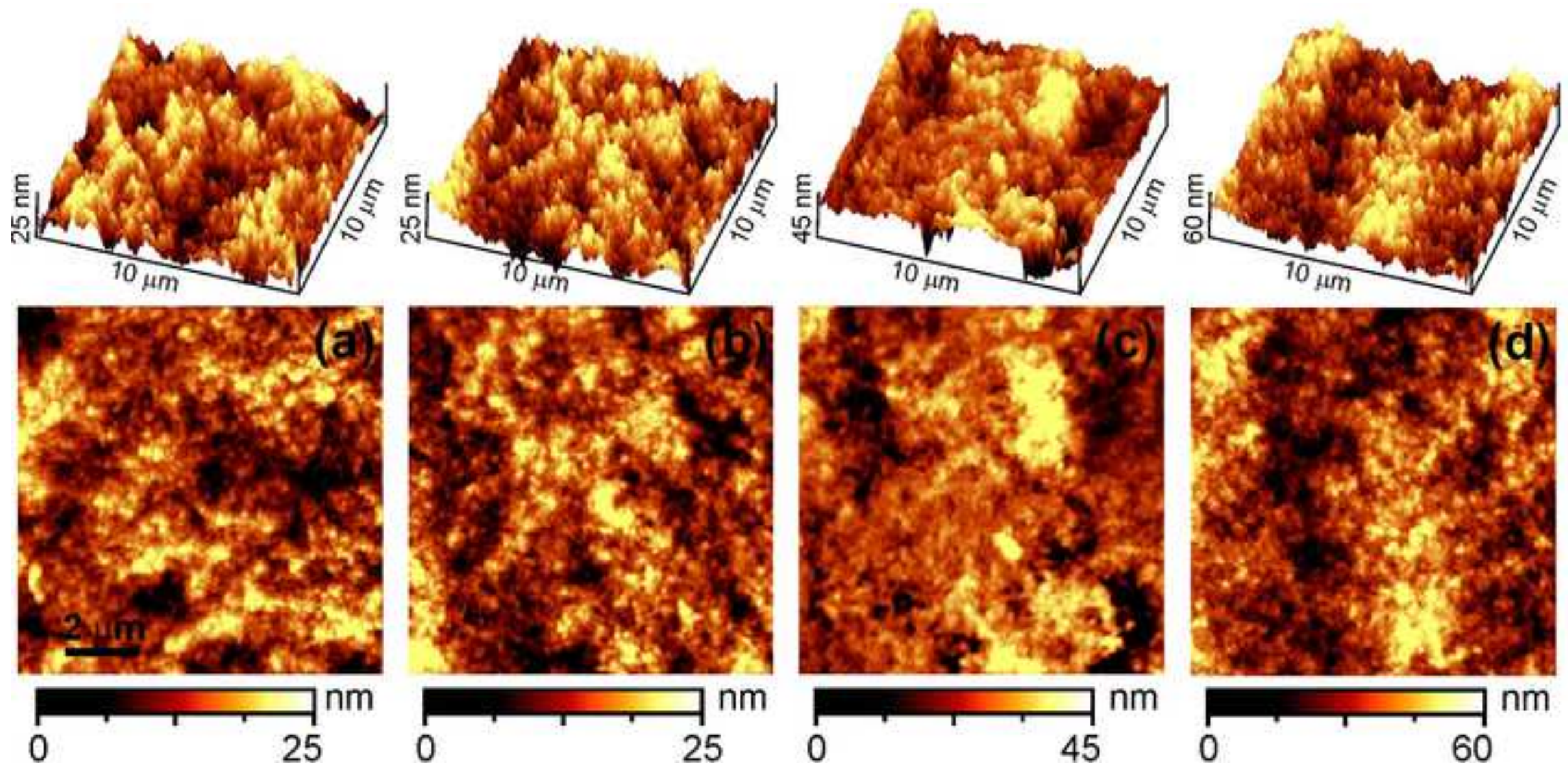


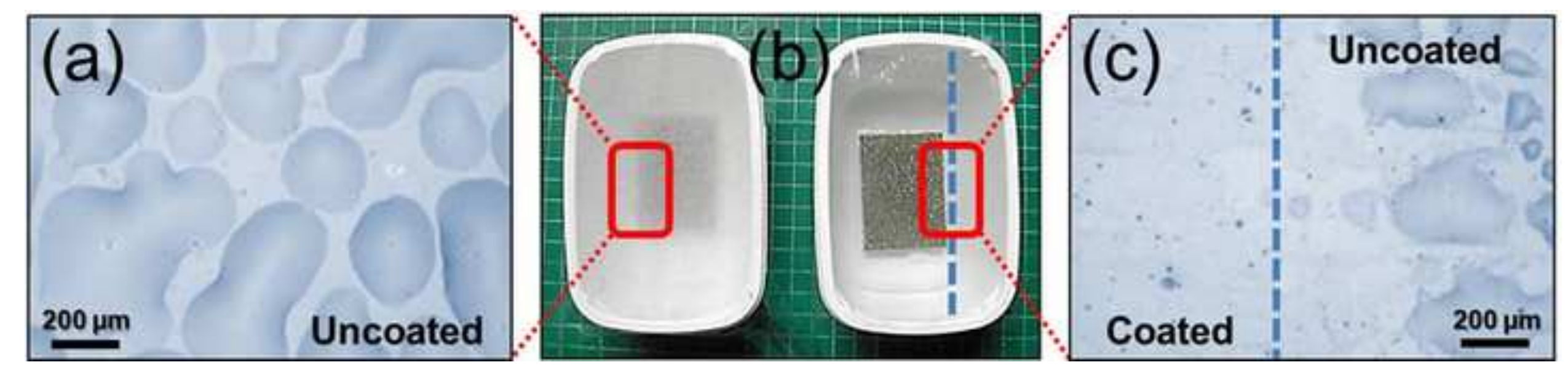




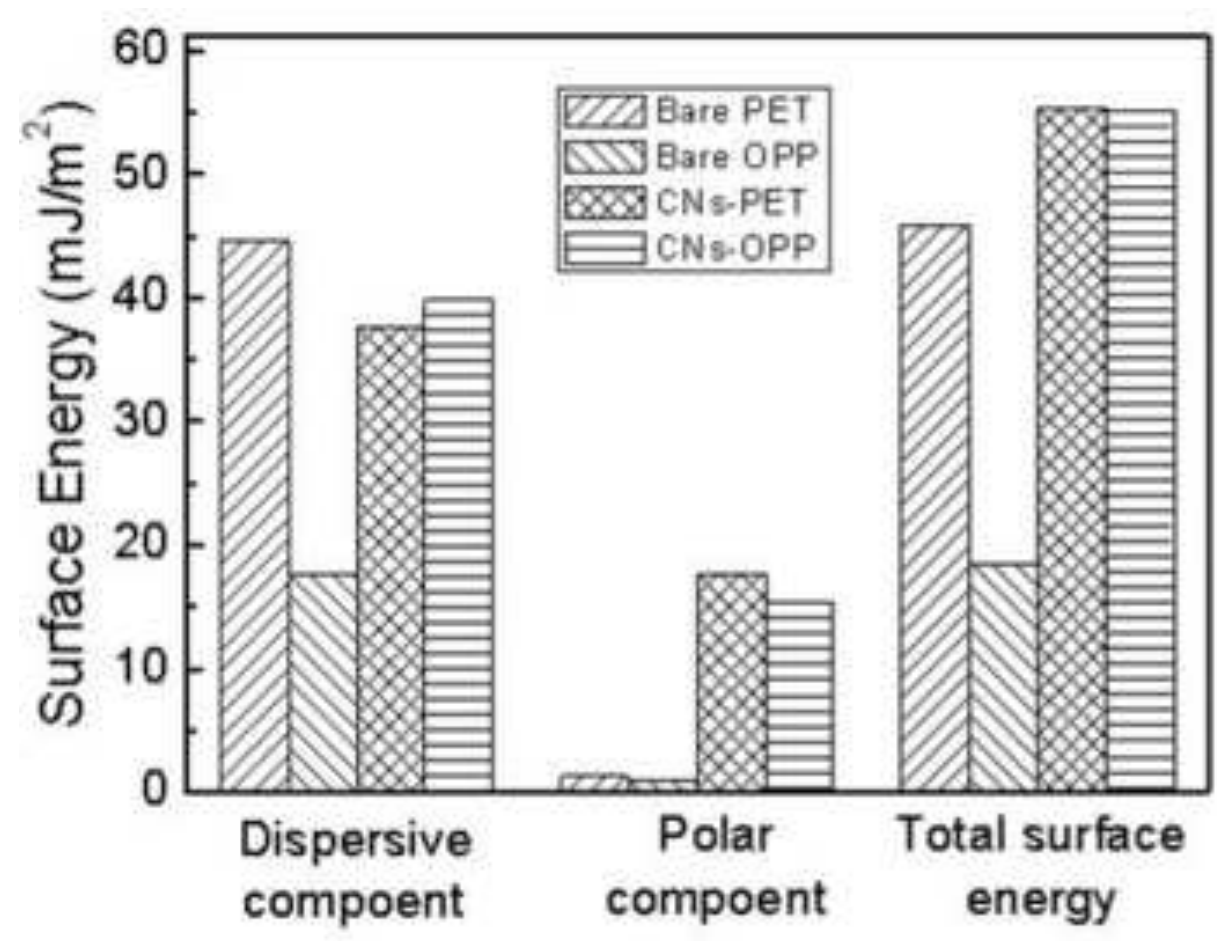

(a)

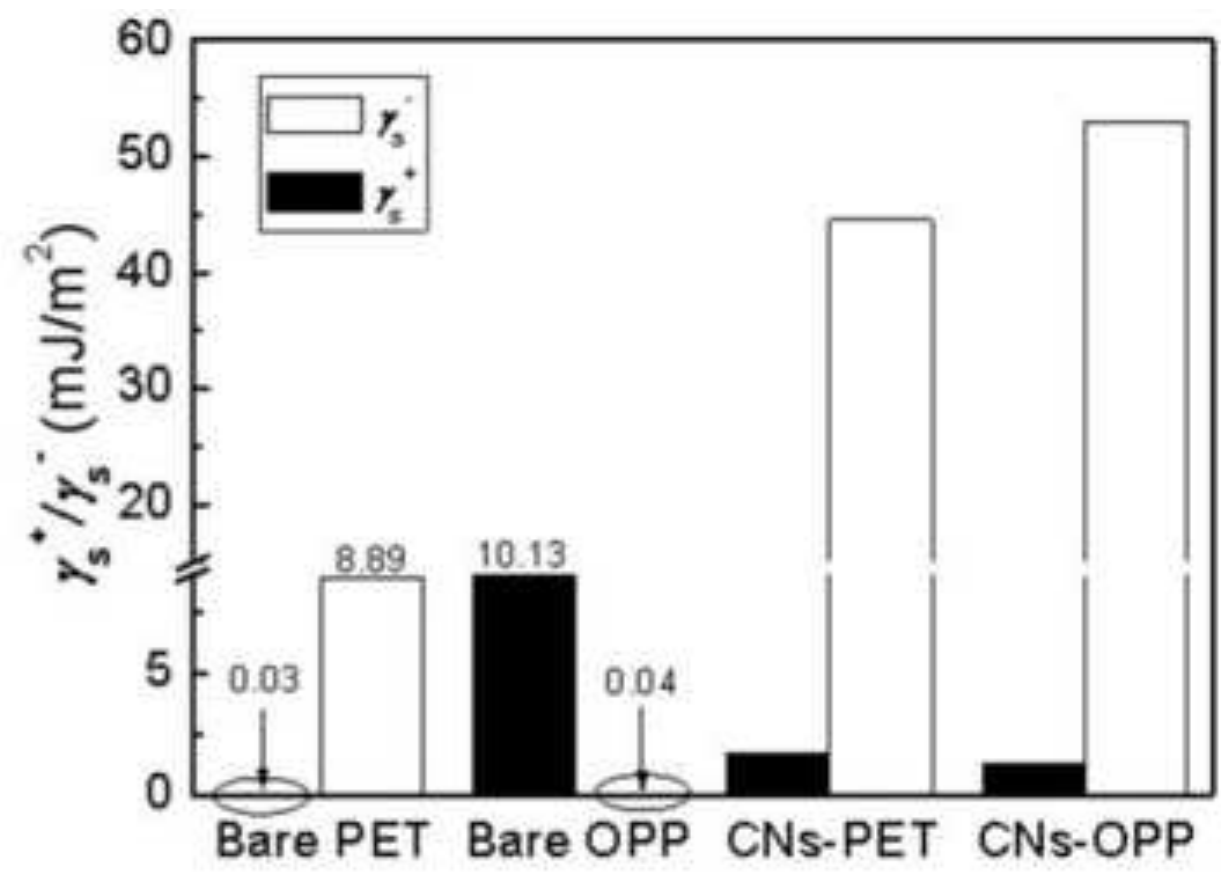

(b) 


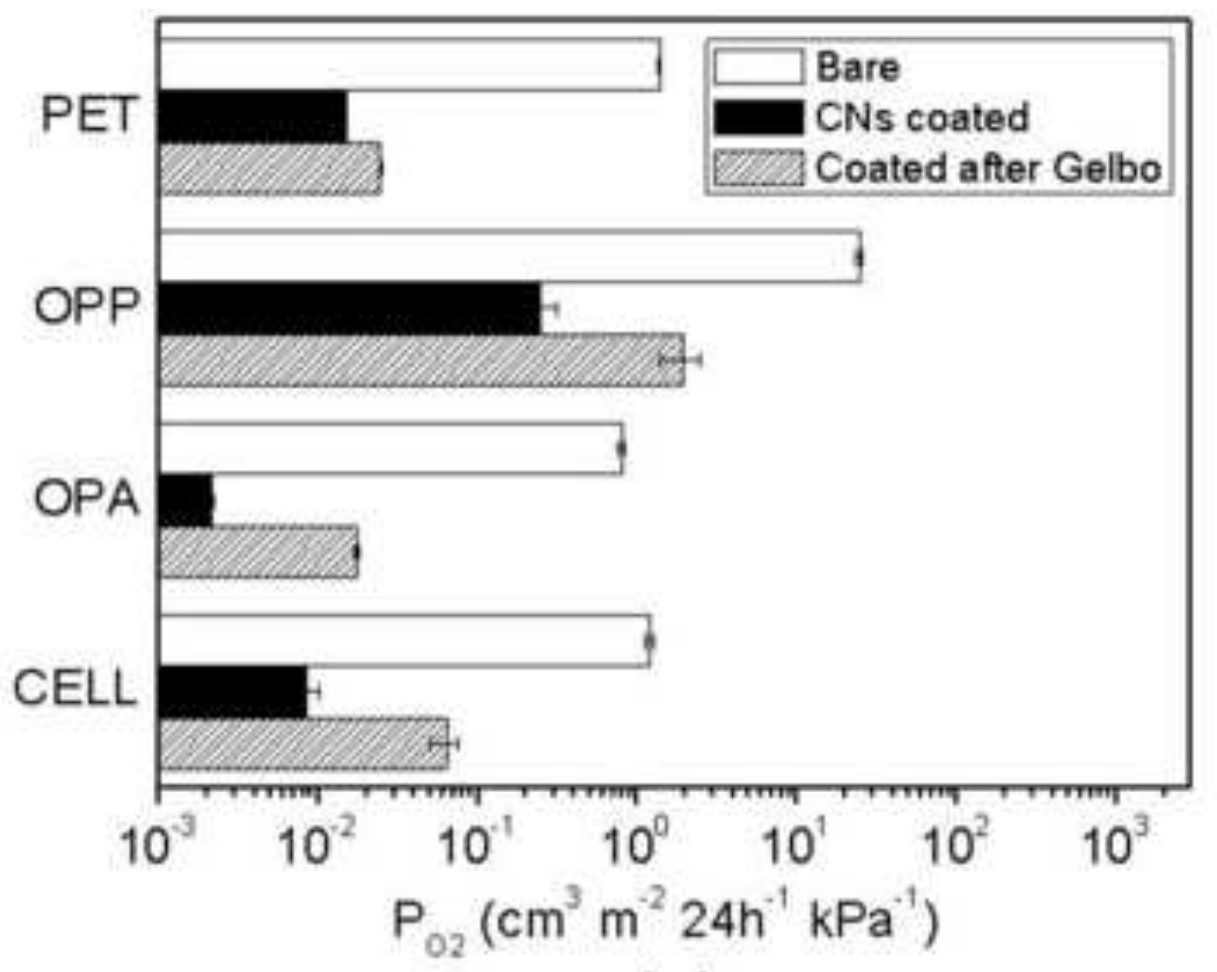

(a)

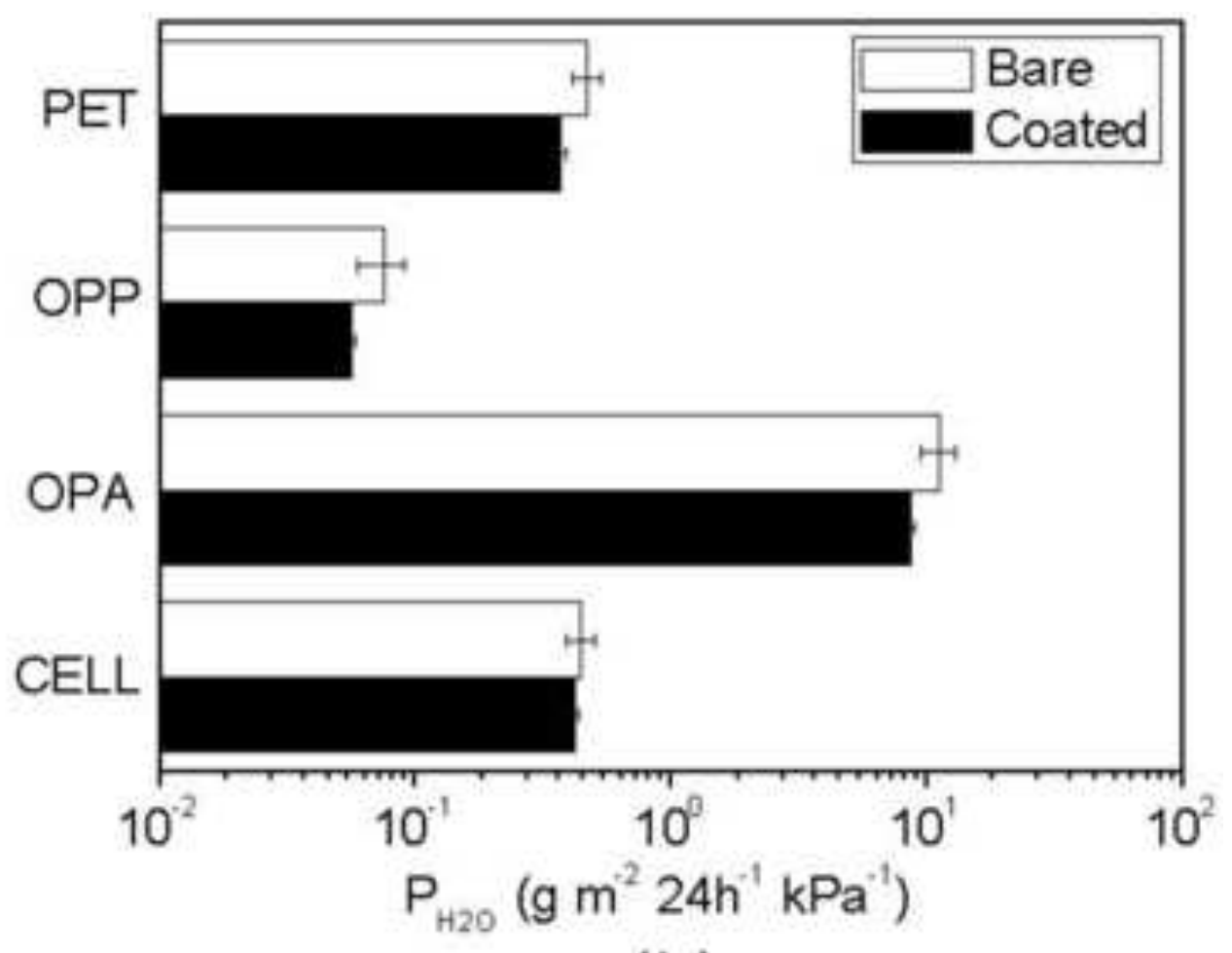

(b) 
Figure9
Click here to download high resolution image
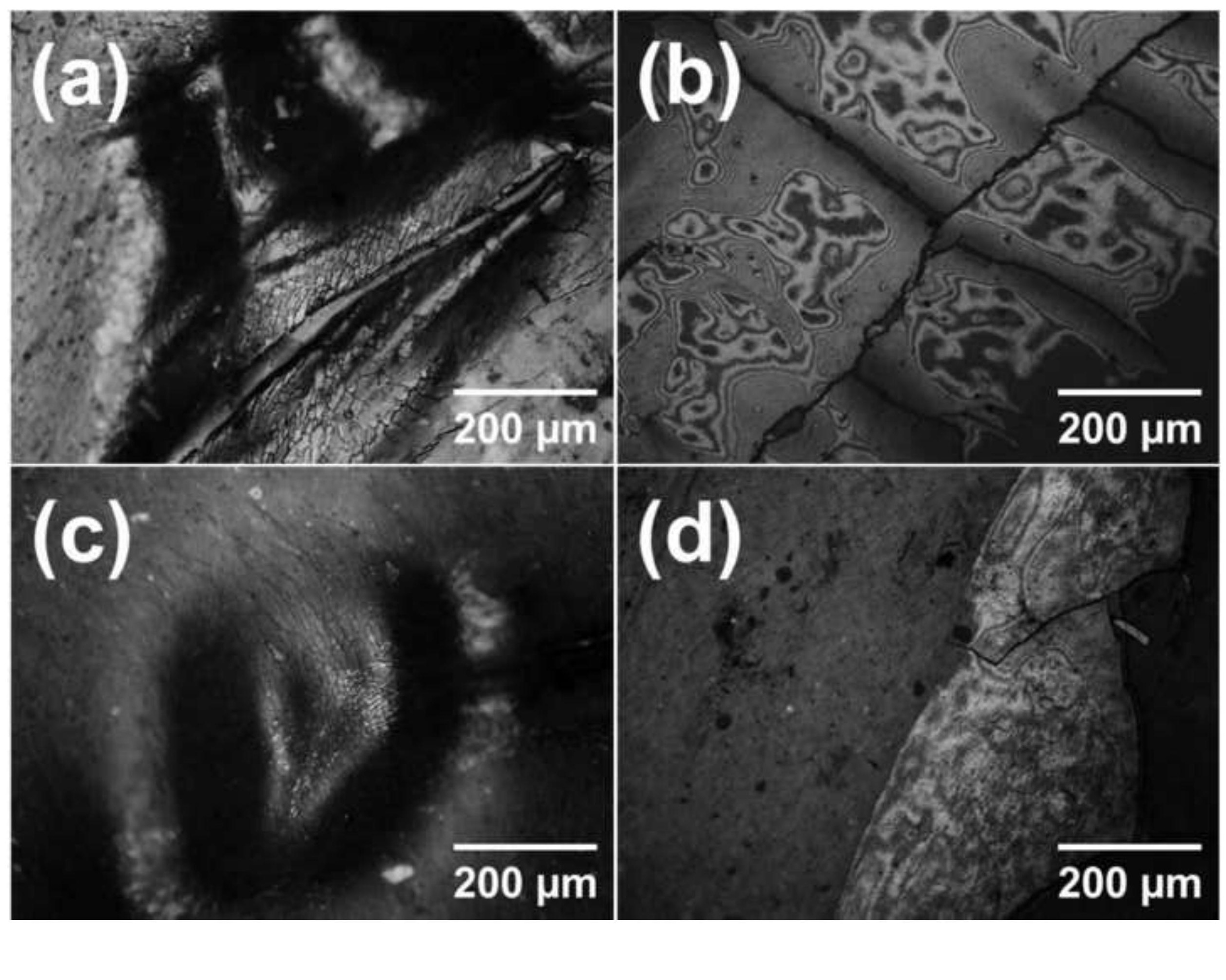
Table 1 Surface tension components and parameters of the liquids used in direct contact angle determination in $\mathrm{mJ} \mathrm{m}^{-2}$, at $20{ }^{\circ} \mathrm{C}$ (van Oss et al., 2001, van Oss, 2003)

\begin{tabular}{|c|c|c|c|c|c|}
\hline Liquid & $\gamma_{l}$ & $\gamma_{l}^{D}$ & $\gamma_{l}^{P}$ & $\gamma_{l}^{+}$ & $\gamma_{l}^{-}$ \\
\hline \multicolumn{6}{|l|}{ APOLAR } \\
\hline Diiodomethane & 50.8 & 50.8 & 0 & $\approx 0.01$ & 0 \\
\hline \multicolumn{6}{|l|}{ POLAR } \\
\hline Water & 72.8 & 21.8 & 51.0 & 25.5 & 25.5 \\
\hline Formamide & 58.0 & 39.0 & 19.0 & 2.28 & 39.6 \\
\hline
\end{tabular}

Table 2 The coefficient of friction (COF) of Plastic films (Ex) against plastic film (In)

\begin{tabular}{|c|c|c|c|c|}
\hline \multirow{2}{*}{ Substrate } & \multicolumn{2}{|c|}{ Bare (Ex) } & \multicolumn{2}{|c|}{ Coated $\left(600 \mathrm{~nm}^{\mathrm{a}}\right)$} \\
\hline & $\mu_{\mathrm{s}}$ & $\mu_{\mathrm{d}}$ & $\mu_{\mathrm{s}}$ & $\mu_{\mathrm{d}}$ \\
\hline PET & $0.57 \pm 0.02^{\mathrm{D}}$ & $0.52 \pm 0.03^{\mathrm{H}}$ & $0.38 \pm 0.01^{\mathrm{C}}$ & $0.33 \pm 0.01^{\mathrm{G}}$ \\
\hline OPP & $0.18 \pm 0.01^{\mathrm{A}}$ & $0.17 \pm 0.00^{\mathrm{F}}$ & $0.30 \pm 0.02^{\mathrm{B}}$ & $0.18 \pm 0.01^{\mathrm{F}}$ \\
\hline OPA & $0.79 \pm 0.02^{\mathrm{E}}$ & $0.74 \pm 0.03^{\mathrm{J}}$ & $0.32 \pm 0.01^{\mathrm{BC}}$ & $0.32 \pm 0.02^{\mathrm{G}}$ \\
\hline CELL & $0.62 \pm 0.03^{\mathrm{D}}$ & $0.57 \pm 0.01^{\mathrm{I}}$ & $0.38 \pm 0.02^{\mathrm{C}}$ & $0.34 \pm 0.01^{\mathrm{G}}$ \\
\hline
\end{tabular}

${ }^{\mathrm{a}}$ Thickness of CNs coating

${ }^{A}$ to ${ }^{\mathrm{E}}$, different letters mean that static COFs are significantly different $(\mathrm{p}<0.01)$;

${ }^{\mathrm{F}}$ to ${ }^{\mathrm{J}}$, different letters mean that dynamic COFs are significantly different $(\mathrm{p}<0.01)$. 
Table 3 Transparency at $550 \mathrm{~nm}$ and haze of bare and CNs-coated films

\begin{tabular}{lcccc}
\hline \multirow{2}{*}{ Substrates } & \multicolumn{2}{c}{ Transparency $(\%)$} & \multicolumn{2}{c}{ Haze (\%) } \\
\cline { 2 - 4 } & Bare & CNs-coated & Bare & CNs-coated \\
\hline PET & $87.5 \pm 0.3$ & $89.0 \pm 0.3$ & $2.9 \pm 0.1$ & $3.3 \pm 0.2$ \\
OPP & $91.8 \pm 0.0$ & $90.8 \pm 0.2$ & $2.1 \pm 0.0$ & $3.4 \pm 0.3$ \\
OPA & $90.2 \pm 0.5$ & $89.8 \pm 0.0$ & $3.0 \pm 0.1$ & $4.0 \pm 0.2$ \\
Cellophane & $87.3 \pm 0.1$ & $88.3 \pm 0.1$ & $3.2 \pm 0.1$ & $3.8 \pm 0.2$ \\
\hline
\end{tabular}

Table 4a Static contact angles of bare and CNs-coated films

\begin{tabular}{lccc}
\hline Films & \multicolumn{3}{c}{ Static CA } \\
\cline { 2 - 4 } & $\theta_{\text {Water }}\left({ }^{\circ}\right)$ & $\theta_{\text {DIM }}\left({ }^{\circ}\right)^{\mathrm{b}}$ & $\theta_{\text {FOM }}\left({ }^{\circ}\right)^{\mathrm{c}}$ \\
\hline Bare PET & $57.44 \pm 5.84$ & $22.41 \pm 2.73$ & $39.55 \pm 1.77$ \\
Bare OPP & $63.03 \pm 1.00$ & $52.22 \pm 1.61$ & $41.39 \pm 1.70$ \\
CNs-PET & $12.32 \pm 1.33$ & $37.15 \pm 3.02$ & $7.41 \pm 1.33$ \\
CNs-OPP & $12.08 \pm 0.95$ & $36.37 \pm 1.70$ & $8.78 \pm 0.73$ \\
\hline
\end{tabular}

Table 4b Advancing and receding contact angles of bare and CNs-coated films

\begin{tabular}{lcccccc}
\hline \multirow{3}{*}{ Films } & \multicolumn{3}{c}{ Advancing CA } & \multicolumn{3}{c}{ Receding CA } \\
\cline { 2 - 7 } & $\theta_{\text {Water }}\left(^{\circ}\right)$ & $\theta_{\text {DIM }}\left({ }^{\circ}\right)^{\mathrm{b}}$ & $\theta_{\mathrm{FOM}}\left({ }^{\circ}\right)^{\mathrm{c}}$ & $\theta_{\text {Water }}\left({ }^{\circ}\right)$ & $\theta_{\mathrm{DIM}}\left({ }^{\circ}\right)^{\mathrm{b}}$ & $\theta_{\mathrm{FOM}}\left({ }^{\circ}\right)^{\mathrm{c}}$ \\
\hline Bare PET & $72.57 \pm 2.96$ & $29.00 \pm 2.12$ & $50.27 \pm 2.97$ & $25.34 \pm 2.12$ & $8.16 \pm 0.82$ & $14.30 \pm 2.76$ \\
Bare OPP & $90.06 \pm 1.84$ & $79.72 \pm 0.69$ & $52.99 \pm 2.65$ & $17.18 \pm 3.41$ & $22.72 \pm 1.26$ & $11.23 \pm 1.38$ \\
CNs-PET & $26.29 \pm 3.27$ & $43.91 \pm 2.03$ & $17.10 \pm 0.74$ & $8.56 \pm 2.23$ & $8.20 \pm 0.34$ & $6.79 \pm 2.01$ \\
CNs-OPP & $27.33 \pm 3.07$ & $39.56 \pm 2.50$ & $17.30 \pm 2.94$ & $5.63 \pm 0.45$ & $7.21 \pm 4.63$ & $5.58 \pm 2.33$ \\
\hline
\end{tabular}

${ }^{\text {a }}$ static contact angle values recorded at $60^{\text {th }}$ second

${ }^{\mathrm{b}}$ DIM, diiodomethane

${ }^{\mathrm{c}}$ FOM, formamide, 